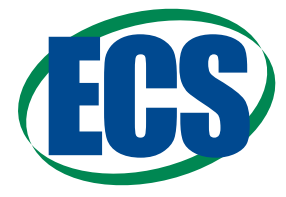

Jes Focus Issue on Advanced Techniques in Corrosion Science in Memory of Hugh Isaacs

\title{
A Complementary Electrochemical Approach for Time-Resolved Evaluation of Corrosion Inhibitor Performance
}

\author{
M. Meeusen, $\oplus^{1, z}$ L. Zardet, ${ }^{2}$ A. M. Homborg, ${ }^{3}$ M. Lekka, ${ }^{2}{ }^{2}$ F. Andreatta, ${ }^{2}$ L. Fedrizzi, ${ }^{2}$ \\ B. Boelen, ${ }^{4}$ H. Terryn, ${ }^{1,5}$ and J. M. C. Mol ${ }^{1}$ \\ ${ }^{1}$ Department of Materials Science and Engineering, Delft University of Technology, 2628 CD Delft, The Netherlands \\ ${ }^{2}$ University of Udine, Polytechnic Department of Engineering and Architecture, Udine, Italy \\ ${ }^{3}$ Netherlands Defence Academy, 1781 AC Den Helder, The Netherlands \\ ${ }^{4}$ Tata Steel IJmuiden B.V., Research and Development, Surface Engineering - Coating Development, IJmuiden, The \\ Netherlands \\ ${ }^{5}$ Research Group of Electrochemical and Surface Engineering (SURF), Vrije Universiteit Brussel, 1050 Brussels, \\ Belgium
}

\begin{abstract}
In this paper, different macroscopic electrochemical techniques are applied to study the corrosion inhibitor efficiency, protection mechanism and stability of a calcium aluminum polyphosphate silicate hydrate inhibitor on hot-dip galvanized steel in the timedomain. Potentiodynamic polarization (PP) measurements are applied to study the anodic and cathodic mechanistic behavior as well as inhibitor efficiencies at discrete and single times of exposure. Open circuit potential (OCP) with superimposed linear polarization resistance (LPR) measurements are applied as a faster, non-invasive alternative to PP, characterizing the overall performance of the system in terms of the polarization resistance. Electrochemical impedance spectroscopy (EIS) measurements are applied to detail both the overall performance of the system as well as the corrosion inhibition mechanism related to the electrochemical system's physicochemical representation over time. Electrochemical noise (EN) measurement are used to evaluate the inhibition efficiency as a function of exposure time, represented by the electrochemical noise resistance. Odd random phase electrochemical impedance spectroscopy (ORP-EIS) is selected as the electrochemical tool to study the system's instability, by evaluation of the non-linearities and non-stationarities over time. The non-stationarities present in the inhibitor-containing electrochemical system are shown to cause the overall instability of the system and should be taken into account when interpreting results from the different techniques over time.

(C) The Author(s) 2019. Published by ECS. This is an open access article distributed under the terms of the Creative Commons Attribution Non-Commercial No Derivatives 4.0 License (CC BY-NC-ND, http://creativecommons.org/licenses/by-nc-nd/4.0/), which permits non-commercial reuse, distribution, and reproduction in any medium, provided the original work is not changed in any way and is properly cited. For permission for commercial reuse, please email: oa@electrochem.org. [DOI: 10.1149/2.0271911jes]
\end{abstract}

(cc) BY-NC-ND

Manuscript submitted March 18, 2019; revised manuscript received May 6, 2019. Published May 16, 2019. This paper is part of the JES Focus Issue on Advanced Techniques in Corrosion Science in Memory of Hugh Isaacs.

Corrosion protection by the application of inhibitor doped organic coatings or the addition of inhibiting species to aqueous corrosive solutions is amongst the most common means of corrosion control strategies for metal applications in aggressive environments. While the use of hexavalent chromium $(\mathrm{Cr}(\mathrm{VI}))$ based corrosion inhibitive chemistries has been common practice for many decades, strict international health and safety legislation including the Registration, Evaluation, Authorisation and Restriction of Chemicals (REACH) regulation of the European Union adopted in 2007, aims to create a new legal framework for the use of hazardous chemical substances. Multiple $\mathrm{Cr}(\mathrm{VI})$ containing compounds, added as active corrosion inhibitors in many polymer formulations because of their exceptional performance, have been or are prone to be phased out in the near future even for demanding applications because of their toxic and carcinogenic nature. ${ }^{1}$ The replacement of these $\mathrm{Cr}(\mathrm{VI})$ based inhibitors by eco-friendly, $\mathrm{Cr}(\mathrm{VI})$-free inhibitors is challenging, since there is a significant performance 'gap' between them. ${ }^{2}$ Different alternatives to the hexavalent chromium technology have been studied, including rare-earth-, vanadate- and lithium- based inhibitors but are not universal and experience some technical constraints, such as upscaling and cost adjustments, to date. ${ }^{3}$

These corrosion protective substances or mixtures, added in low concentration, prevent or minimize the corrosion rate of a variety of metal substrates. Apart from their chemical nature, they can also be classified according to their working principle as anodic, cathodic or mixed type corrosion inhibitors. ${ }^{4,5}$ Anodic inhibitors typically form or facilitate the formation of a protective oxide film on the metal matrix and consequently shift the corrosion potential into the passive range. Cathodic inhibitors either slow down the cathodic reactions themselves or form precipitates on cathodic areas, reducing the diffusion

zE-mail: M.Meeusen@tudelft.nl of electrolyte, oxygen and water to the surface. Mixed corrosion inhibitors impact both the anodic and cathodic reactions. In all cases, the presence of corrosion inhibitors changes the overall electrochemistry and reduces the corrosion reaction kinetics over time. ${ }^{4-6}$

Up to now, multiple studies applying a variety of electrochemical characterization techniques exist to study $\mathrm{Cr}(\mathrm{VI})$-free corrosion inhibitors and investigate their performance for a given metallic substrate. However, few works are dedicated to the comparison between stationary and non-stationary techniques to study electrochemical systems.?

Potentiodynamic polarization (PP) experiments describe the kinetic behavior of an inhibitor-containing electrochemical system by decoupling the anodic and cathodic reactions on the surface under investigation. Zin, Pokhmurs'kyi et al. studied the synergistic effect of phosphate and calcium-containing pigments on the corrosion resistance of galvanized steel with PP to distinguish between anodic, cathodic or mixed control at discrete immersion times. ${ }^{8,9}$ Deflorian et al. used PP measurements to study the anodic and cathodic corrosion mechanism separately for the corrosion protection performance of primers containing polyphosphate-based ion-exchange pigments for galvanized steel. ${ }^{10}$ Kartsonakis et al. screened six possible corrosion inhibitors for hot-dip galvanized steel with PP experiments and differentiated between anodic and cathodic inhibitors in terms of anodic and cathodic current density and by a shift in the open circuit potential (OCP) ${ }^{11}$ Hernandez-Alvarado et al. studied a chromate-free organic inhibitor for galvanized steel with PP to identify the oxidation and reduction reactions and the related increase and decrease in corrosion current density. ${ }^{12}$

The polarization resistance method or Stern-Geary method is a well-established technique for the determination of corrosion rates. ${ }^{13}$ Through linear polarization resistance (LPR) measurements using a small amplitude excitation potential and measuring the current density 
response, the polarization resistance $\left(\mathrm{R}_{\mathrm{p}}\right)$ can be calculated from the slope of the potential versus current density slope around the corrosion potential $\left(\mathrm{E}_{\text {corr }}\right)$. Subsequently, the corrosion current density and the corrosion rate can be determined through the Stern-Geary coefficient (B). ${ }^{13-15}$ Moreover, LPR measurements could be applied as such to determine the corrosion protective properties of inhibitor-containing systems over time. Kartsonakis et al. applied the LPR technique for the characterization of different corrosion inhibitors for hot-dip galvanized steel after $168 \mathrm{~h}$ to compare their inhibition performance. ${ }^{11}$ Hernadez-Alvarado et al. used the $R_{p}$ method to evaluate the protective properties of a chromate-free organic inhibitor for galvanized steel at discrete times over a period of 140 days. These observations were coupled to the protective mechanism through anodic and cathodic polarization measurements. ${ }^{12,16}$ However, complications may occur regarding the potential scan rate as well as with non-linear and non-stationary behavior of the system under investigation since this method de facto assumes linear and time-invariant electrochemical behavior. $^{13,15}$

Electrochemical impedance spectroscopy (EIS) has manifested itself as a powerful technique to screen and study the corrosion protective properties of corrosion inhibitors over time both qualitatively and quantitatively. The former refers to the comparison of the magnitude of the impedance modulus at low frequencies over time. ${ }^{17}$ The latter corresponds to the fitting of the impedance data to a physicochemical sound equivalent electrical circuit so that the individual contributions to the overall system's performance can be quantified. ${ }^{8,9,18}$

However, since corrosion processes are intrinsically non-linear and non-stationary, ${ }^{19}$ trustworthy EIS measurements can only be carried out if it is proven that the inhibitor-containing electrochemical system is linear and time-invariant within the timeframe of the measurement. ${ }^{20}$ A number of possible solutions have been proposed lately. Application of the Kramers-Kronig (K-K) transforms provide verification criteria with respect to the linearity and stationary conditions. Nevertheless it has been illustrated that the conformity with the condition of timeinvariance is difficult to deal with. ${ }^{21-23}$ Generally, in other works, EIS measurements are only performed after stabilization of the OCP with a small amplitude of the excitation signal, supposing the respective conditions to be fulfilled. Hamlaoui et al. waited for 30 minutes prior to performing an EIS measurement, using an signal amplitude of $10 \mathrm{mV}$ when monitoring the corrosion of galvanized coatings and presuming linearity and stationarity during measuring. ${ }^{24}$ Kartsonakis et al. studied the corrosion protective mechanisms of inhibitors for hot-dip galvanized steel with a signal amplitude of $10 \mathrm{mV}$ root mean square (RMS) but first allowing the system to stabilize for one hour. ${ }^{11}$ Deflorian et al. studied cerium oxides as corrosion inhibitors for galvanized steel using EIS with a signal amplitude of $5 \mathrm{mV}$ starting from one hour after immersion. ${ }^{12}$ Consequently the initial, rapidly evolving stages of corrosion inhibitor-containing electrochemical processes prior to the first EIS measurement cannot be described adequately. ${ }^{25}$

Electrochemical noise (EN) measurements have proven to be a suitable technique for in-depth corrosion analysis. When two identical working electrodes are connected through a zero resistance ammeter (ZRA) and with a potentiometer to a reference electrode, one can differentiate between different types of corrosion processes. Moreover, through alternative transient analysis methods, non-stationary electrochemical processes can be described. ${ }^{26}$ Homborg et al. successfully identified localized corrosion of stainless steel, corrosion inhibition on AA2024-T3 by Ce ions and microbiologically influenced corrosion of carbon steel using EN. ${ }^{27-29}$

Odd random phase electrochemical impedance spectroscopy (ORP-EIS) is a multisine EIS technique providing information about the linearity and time-invariance of electrochemical systems. Here, the system is excited with a multisine signal over the entire frequency range instead of exciting the electrochemical system at each subsequent frequency. This periodic broadband signal comprises harmonically related sine waves whereof only the odd harmonics are excited and one out of three consecutive harmonics is randomly omitted. ${ }^{30}$ The linearity and time-invariant information is then obtained through a dedicated data analysis procedure. The concept of ORP-EIS has al- ready been demonstrated to be a successful tool to study non-linear and particularly non-stationary electrochemical systems. Fernández Macía et al. studied the electron transfer inhibition on a charged selfassembled monolayer modified gold electrode and the time-varying characteristics of the electron transfer of the ferri/ferrocyanide reaction on gold. ${ }^{31,32}$ Alvarez-Pampliega et al. investigated the initial nonstationary corrosion process of aluminum rich metal coated steel. ${ }^{33}$ Hauffmann et al. used ORP-EIS to study the growth of self-assembled monolayers on aluminum oxides in-situ, which is essentially nonstationary. ${ }^{34,35}$ By the detection of non-linearities and especially nonstationarities, the onset of corrosion on coated steel was studied by Breugelmans et al. ${ }^{36}$ Recently Ji et al. studied the corrosion behavior of hot dip galvanized steel wires in sodium chloride solution. The initial, non-stationary corrosion behavior was linked with the microstructural properties of the steel wires. ${ }^{37}$ In earlier work we already highlighted the time-dependent behavior of inhibitor-containing electrochemical systems. The presence of non-stationarities in a certain frequency range was linked to the trends in the evolution of the equivalent electrical circuit (EEC) parameters and the unstable behavior of the electrochemical processes could be related to the associated morphological changes. ${ }^{25}$

Beyond the scope of the present study, the macroscopic study of corrosion inhibitors is often coupled to dedicated surface analysis measurements or alternatively, the study of corrosion inhibitors is approached from a local electrochemical point of view.

In this paper, different macroscopic electrochemical techniques are applied to study corrosion inhibitor efficiency, protection mechanism and stability of a calcium aluminum polyphosphate silicate hydrate inhibitor on hot-dip galvanized steel in the time-domain. While the search for optimized inhibitor performance in itself was out of scope of this work, a phosphate based inhibitor was chosen as the corrosion inhibitor of study as in its basics and chemistry it represents an industrially and commonly applied inhibitor class. PP is used to determine the inhibitor working principle and efficiency at a single time of exposure. The application of repetitious LPR measurements superimposed on a continuous OCP measurement is used as a non-invasive alternative to measure the corrosion inhibitor performance over time. EIS is applied to study also the working mechanism of the corrosion inhibitor over time. EN measurements are applied to identify the corrosion inhibition efficiency as a function of exposure time, represented by the electrochemical noise resistance. ORP-EIS is used to quantify the stability of the corrosion inhibitor over time. Initially, the mechanistic, efficiency and stability information obtained from the different techniques is discussed separately. Finally, a comparison between the information obtained with the different electrochemical techniques is made in the time-domain, in order to evaluate the complementarity of the macroscopic electrochemical techniques used in this study.

\section{Experimental}

Materials and sample preparation.-Hot-dip galvanized steel was obtained from Tata Steel, IJmuiden The Netherlands, with an average coating mass of $275 \mathrm{~g} \cdot \mathrm{m}^{-2}$ and nominal composition of the steel substrate and galvanized coating as listed in Table I. The galvanized steel samples were cut to $30 \mathrm{~mm}$ by $50 \mathrm{~mm}$, with a circular exposed area of $2.01 \mathrm{~cm}^{2}$ for PP, LPR, EIS and ORP-EIS and $0.28 \mathrm{~cm}^{2}$ for EN measurements. However, all results are surface area corrected. The samples were then alkaline cleaned according to ASTM D 6386-99: the samples were cleaned with acetone for 5 minutes in the ultrasonic bath. Then, the samples were immersed in a $1 \mathrm{M} \mathrm{NaOH}$ solution, adjusted to $\mathrm{pH} 12$ with $\mathrm{H}_{3} \mathrm{PO}_{4}$, for 30 seconds. Finally, the samples were rinsed with distilled water and dried.

Heucophos CAPP, a calcium aluminum polyphosphate silicate hydrate provided by Heubach, Langelsheim Germany, was used as a zinc-free phosphate corrosion inhibitor for hot-dip galvanized steel. ${ }^{38}$ The reference solution used for all measurements was $0.05 \mathrm{M} \mathrm{NaCl}$, relevant for building construction steel applications. Moreover, this concentration is preferred for future local electrochemical research. 
Table I. Nominal composition of the hot-dip galvanized steel substrate and the galvanized coating.

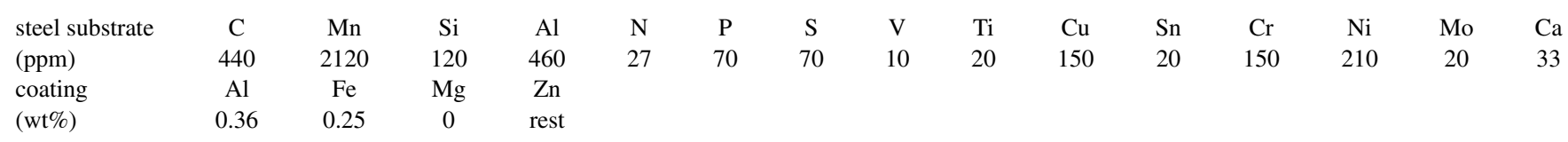

Based on this, a $0.5 \mathrm{mM}$ solution of the corrosion inhibitor was prepared.

X-ray Fluorescence (XRF) analysis was carried out to determine the molar mass of the corrosion inhibitor and to make the correct corrosion inhibitor solution. The measurements on the pressed powders were performed with a Panalytical Axios Max WD-XRF spectrometer and the data evaluation was done with SuperQ5.0i/Omnian software. XRF analysis on Heucophos CAPP revealed the presence of silica (34.46 wt \%), phosphorous pentoxide (29.40 wt $\%$ ), calcium oxide $(25.89 \mathrm{wt} \%)$ and alumina $(8.83 \mathrm{wt} \%)$ as main components.

Electrochemical techniques.-Potentiodynamic polarization.A typical three electrode set-up was used for the PP experiments with an $\mathrm{Ag} / \mathrm{AgCl} 3 \mathrm{M} \mathrm{KCl}$ reference electrode, a graphite bar as the counter electrode and the hot-dip galvanized steel as the working electrode.

PP curves after 1.5 hours, after stabilization of the OCP, and after 24 hours were acquired by measuring the anodic and cathodic branch separately, using different hot-dip galvanized steel samples and for at least three times per system with or without corrosion inhibitor. The cathodic branch was measured starting from $+30 \mathrm{mV}$ to $-500 \mathrm{mV}$ relative to the OCP and the anodic branch was measured from $-30 \mathrm{mV}$ to $+500 \mathrm{mV}$ relative to the OCP ensuring a small overlap between both branches around the OCP. The scan rate applied was $1 \mathrm{mV} / \mathrm{s}$ and a measurement point was taken every $0.2 \mathrm{~s}$. The Tafel extrapolation procedure has been applied to determine the corrosion potential $\left(\mathrm{E}_{\text {corr }}\right)$ and the corrosion current density ( $\left.\mathrm{i}_{\text {corr }}\right)$. The $\mathrm{E}_{\text {corr }}$ value was then compared versus the OCP value to evaluate the quality of the extrapolation and the $i_{\text {corr }}$ value was used to calculate the inhibitor efficiency $\eta(\%)$. All results presented in this work are rounded according to the twodigits rule: the standard deviation is rounded to two significant digits, and the mean is then matched accordingly to the decimal places of the standard deviation. ${ }^{39,40}$

Open circuit potential with superimposed linear polarization resistance.-A typical three electrode set-up was used for the OCP with superimposed LPR experiments with an $\mathrm{Ag} / \mathrm{AgCl} 3 \mathrm{M} \mathrm{KCl}$ reference electrode, a graphite bar as the counter electrode and the hot-dip galvanized steel as the working electrode.

The OCP has been monitored for 168 hours, while performing a superimposed LPR measurement every hour with an amplitude of $\pm 5 \mathrm{mV}$ relative to the OCP at a scan rate of $0.1667 \mathrm{mV} / \mathrm{s}$ on at least three samples per system with or without corrosion inhibitor. The $R_{p}$ was calculated from the slope from the potential versus current graph at the corrosion potential $\mathrm{E}_{\text {corr }}{ }^{41}$

Electrochemical impedance spectroscopy.-A typical three electrode set-up, placed in a Faraday cage, was used for the electrochemical experiments with an $\mathrm{Ag} / \mathrm{AgCl} 3 \mathrm{M} \mathrm{KCl}$ reference electrode, a stainless steel grid as the counter electrode and hot-dip galvanized steel as the working electrode with an area of $2.01 \mathrm{~cm}^{2}$.

The EIS measurements on at least three samples per system with or without corrosion inhibitor were performed with a Biologic VMP300 multichannel potentiostat in a frequency range from $10^{-2} \mathrm{~Hz}$ to $10^{5} \mathrm{~Hz}$, with 7 points per decade. The amplitude of the excitation signal was set to $10 \mathrm{mV}$, relative to the OCP. Measurements were performed every 30 minutes, while the OCP was monitored in between, for a total duration of 168 hours. The impedance data were fitted with different equivalent electrical circuits using Zview from Scribner Associates Inc.
Electrochemical noise.-A conventional three electrode set-up was used for the EN experiments with two identical hot-dip galvanized steel working electrodes and an $\mathrm{Ag} / \mathrm{AgCl} 3 \mathrm{M} \mathrm{KCl}$ reference electrode, under open-circuit conditions. A well-defined area of $0.28 \mathrm{~cm}^{2}$ of each working electrode was exposed to the electrolyte. The electrochemical cells were placed in a Faraday cage to avoid electromagnetic disturbance from external sources. Potential and current signals were recorded using a Compactstat from Ivium Technologies working as potentiometer and ZRA on at least three samples per system with or without corrosion inhibitor. The sampling frequency was set to $20 \mathrm{~Hz}$. A low-pass filter of $10 \mathrm{~Hz}$, which is the Nyquist frequency at this sampling rate, was applied during data recording. The minimum and maximum ranges of the ZRA were automatically determined during the measurements, depending on the dynamic range of the electrochemical current noise signal locally, with a lower limit of $1 \mathrm{nA}$ and an upper limit of $100 \mu \mathrm{A}$. The range of the potentiometer was set at $40 \mathrm{mV}$ with the removal of the initial DC drift component. The data were processed using Matlab from Mathworks. ${ }^{28,42,43}$

Odd random phase electrochemical impedance spectroscopy.-A typical three electrode set-up was used for the electrochemical experiments with an $\mathrm{Ag} / \mathrm{AgCl} 3 \mathrm{M} \mathrm{KCl}$ reference electrode, a stainless steel grid as the counter electrode and the hot-dip galvanized steel sample as the working electrode. The set-up was placed in a Faraday cage. Measurements were recorded immediately after immersion in both the reference and corrosion inhibitor solution and continued for 24 hours. In both cases, a measurement was taken every 15 minutes. The measurements on each system, with or without corrosion inhibitors, was repeated at least once for consistency.

The ORP-EIS measurements were performed with a MATLAB controlled set-up comprising of a Bio-Logic SP-200 potentiostat and a National Instruments PCI-6110 DAQ card. The frequency range was from $10^{-2} \mathrm{~Hz}$ to $2 \cdot 10^{3} \mathrm{~Hz}$. The amplitude of the excitation signal was set to $3 \mathrm{mV}$ (2.12 $\mathrm{mV}$ root mean square (RMS)) in the case of hot-dip galvanized steel without corrosion inhibitor and $5 \mathrm{mV}$ (3.54 mV RMS) in the case of hot dip galvanized steel with corrosion inhibitor, applied relative to the OCP, to have a good signal-to-noise ratio while keeping the non-linearities confined. The MATLAB software to build the odd random phase multisine excitation signal, record the impedance measurements and perform the modelling was developed at the Vrije Universiteit Brussel. A more detailed description of this technique can be found elsewhere. ${ }^{20,44}$

\section{Results and Discussion}

Potentiodynamic polarization.-PP measurements were performed to obtain information about the corrosion inhibitor's working mechanism and efficiency. In Figure 1a, the PP curves for hot-dip galvanized steel with and without corrosion inhibitor after 1.5 hours and 24 hours are presented. The system with corrosion inhibitor after 1.5 hours shows lower cathodic current densities as compared to the system without corrosion inhibitor after 1.5 hours, but only marginal anodic inhibition. After 24 hours, the system with corrosion inhibitor demonstrates similar behavior, while the system without inhibitors shows a significant increase in cathodic current density. These observations suggest a cathodic inhibition behavior, in agreement with an earlier study of calcium-aluminum-polyphosposilicahydrate pigments for the protection of galvanized steel by Deflorian et al. ${ }^{10}$

In Figure 1b, the corrosion current density, obtained through Tafel extrapolation, ${ }^{45}$ after 1.5 hours and 24 hours is plotted for the hot-dip galvanized steel with and without corrosion inhibitor. In the case of 

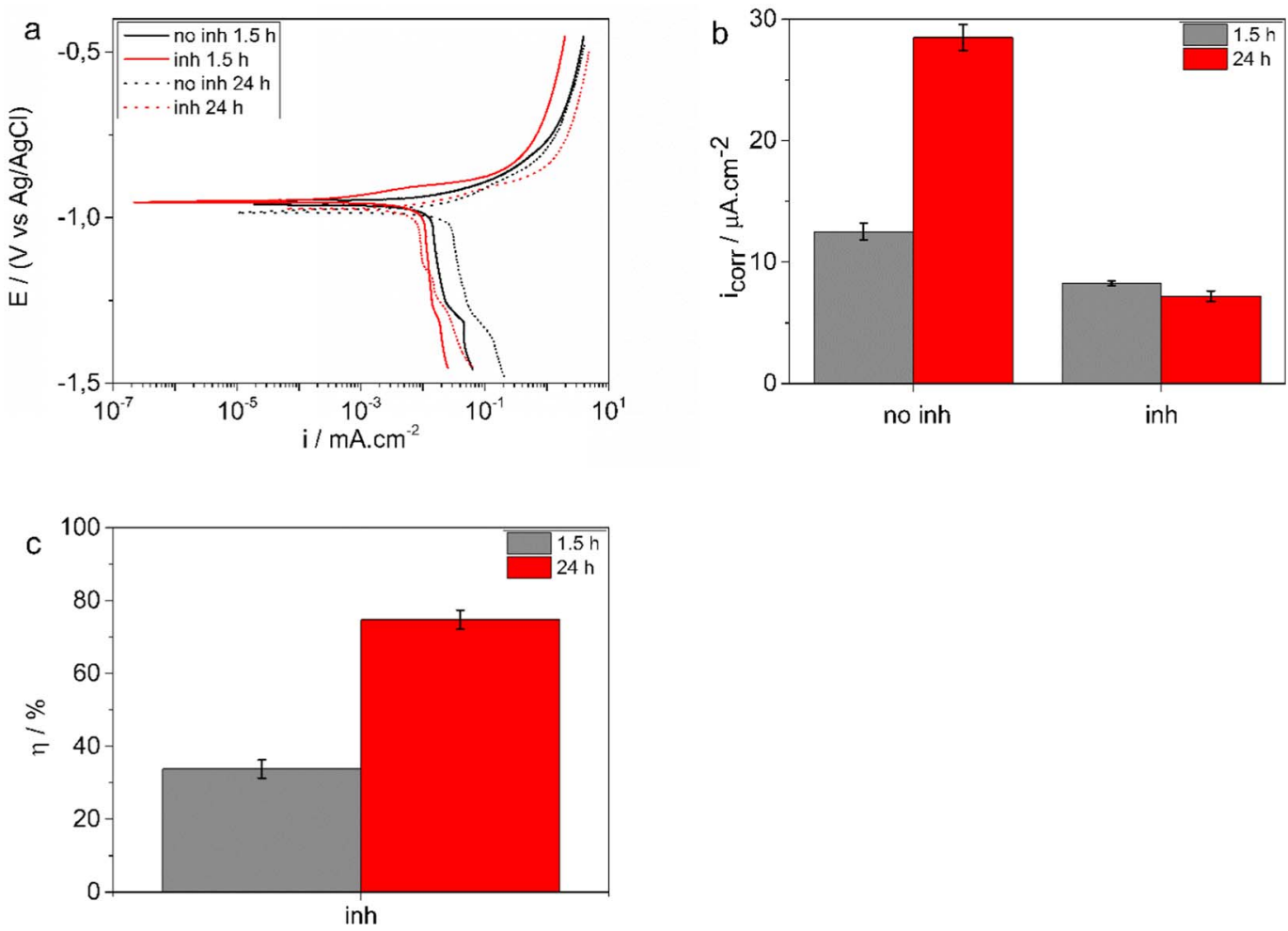

Figure 1. Potentiodynamic polarization diagram (a), corrosion current density (i $\mathrm{i}_{\text {corr }}$ ) (b) and corrosion inhibitor efficiency ( $\mathrm{n}$ ) (c) of hot-dip galvanized steel without $(0.05 \mathrm{M} \mathrm{NaCl})$ and with corrosion inhibitor $(0.5 \mathrm{mM}$ Heucophos CAPP) after $1.5 \mathrm{~h}$ and $24 \mathrm{~h}$.

the reference solution, the corrosion current density increased from $12.50 \pm 0.71 \mu \mathrm{A} \mathrm{cm}^{-2}$ after 1.5 hours to $28.5 \pm 1.1 \mu \mathrm{A} \mathrm{cm}^{-2}$ after 24 hours. The \pm values represent the standard deviation on each measurement. In the case of the corrosion inhibitor containing solution, $\mathrm{i}_{\text {corr }}$ decreased from $8.28 \pm 0.20 \mu \mathrm{A} \mathrm{cm}^{-2}$ after 1.5 hours to $7.20 \pm$ $0.43 \mu \mathrm{A} \mathrm{cm}^{-2}$ after 24 hours. This shows the active corrosion process of the hot-dip galvanized steel without corrosion inhibitor and the effective corrosion inhibition of the hot-dip galvanized steel with $0.5 \mathrm{mM}$ of corrosion inhibitor.

In order to assess the effectiveness of corrosion inhibitor, the corrosion inhibitor efficiency $(\eta)$ is calculated from the corrosion current density of the inhibited system $\left(i_{\text {corr(inh) }}\right)$ and the reference $\left(i_{\text {corr }}\right)$ according to: ${ }^{46}$

$$
\eta(\%)=\frac{i_{\text {corr }}-i_{\text {corr }(i n h)}}{i_{\text {corr }}} \times 100
$$

In Figure 1c, the corrosion inhibitor efficiency is plotted after 1.5 hours and 24 hours. The corrosion inhibitor efficiency approximately doubles from $33.8 \pm 2.5 \%$ to $74.7 \pm 2.7 \%$ after 1.5 hours and 24 hours, respectively. However, this increase in efficiency can be attributed primarily to the relatively large increase $(+128 \%)$ of the corrosion current density of the reference system rather than the minor decrease $(-13 \%)$ of the corrosion current density of the inhibited system.

It can be concluded that PP measurements can provide detailed mechanistic information in terms of the anodic and cathodic stationary behavior at discrete times of immersion. However, obtaining timeresolved information on inhibitor performance and efficiency is time intensive.

Open circuit potential with superimposed linear polarization resistance.-In order to characterize the performance of the system in the first 168 hours after immersion with and without the presence of corrosion inhibitors, continuous OCP measurements with coupled LPR measurements every hour were carried out. From the slope of the potential versus current plot for every hour, the $R_{p}$ can be calculated and as such monitored every hour.
Figure 2 shows the $\mathrm{R}_{\mathrm{p}}$ values and their standard deviation of the hotdip galvanized steel with and without corrosion inhibitor over time. It can be seen that in the case of the reference solution, the $R_{p}$ is $1.65 \pm$ $0.14 \mathrm{k} \Omega \mathrm{cm}^{2}$ after 1 hour, decreasing rapidly in the first 10 hours to $0.99 \pm 0.12 \mathrm{k} \Omega \mathrm{cm}^{2}$ and eventually continuing to decrease slowly to $0.61 \pm 0.11 \mathrm{k} \Omega \mathrm{cm}^{2}$ after 168 hours of immersion. In the case of hotdip galvanized steel with corrosion inhibitor, the $R_{p}$ is $1.51 \pm 0.48 \mathrm{k} \Omega$ $\mathrm{cm}^{2}$ at the start and decreases gradually in the first 8 hours to $1.274 \pm$ $0.064 \mathrm{k} \Omega \mathrm{cm}^{2}$. Afterwards a gradual increase is noticeable to $1.56 \pm$ $0.19 \mathrm{k} \Omega \mathrm{cm}^{2}$ after 168 hours, which is more than two times higher compared to the reference solution.

The $\mathrm{R}_{\mathrm{p}}$ value for the sample without corrosion inhibitor after 1 hour is in good agreement with the value of $2.049 \mathrm{k} \Omega \mathrm{cm}^{2}$ obtained by Kartsonakis et al. after 1 hour of immersion in $0.05 \mathrm{M} \mathrm{NaCl}^{11}$

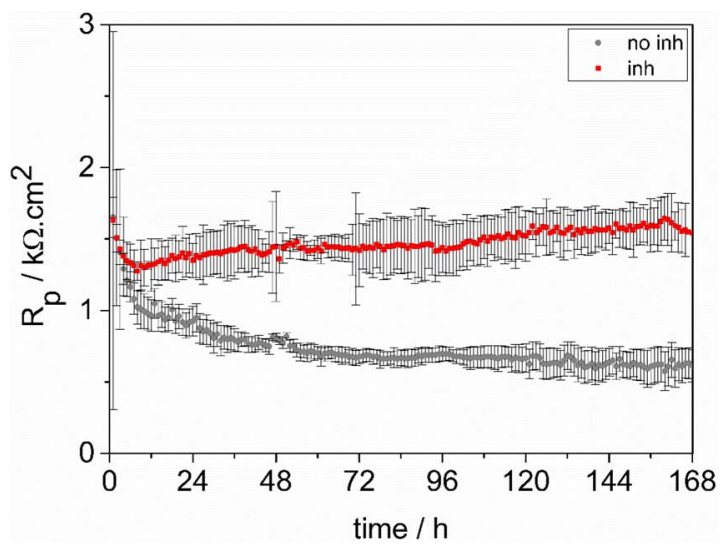

Figure 2. Polarization resistance $\left(\mathrm{R}_{\mathrm{p}}\right)$ results and their standard deviation obtained from linear polarization resistance measurements of hot-dip galvanized steel without $(0.05 \mathrm{M} \mathrm{NaCl})$ and with corrosion inhibitor $(0.5 \mathrm{mM}$ Heucophos CAPP) for $168 \mathrm{~h}$. 
Table II. Tafel Parameters from PP and $R_{p}$ from LPR for the determination of $i_{\text {corr }}$ using Stern-Geary.

\begin{tabular}{cccccccc} 
& time & $\mathrm{R}_{\mathrm{p}}\left(\mathrm{k} \Omega \mathrm{cm}^{2}\right)$ & std. dev. $\left(\mathrm{k} \Omega \mathrm{cm}^{2}\right)$ & $\beta_{\mathrm{a}}(\mathrm{V} / \mathrm{dec})$ & $\beta_{\mathrm{c}}(\mathrm{V} / \mathrm{dec})$ & $\mathrm{i}_{\text {corr }}\left(\mu \mathrm{Acm} \mathrm{cm}^{-2}\right)$ & \multicolumn{1}{c}{ std. dev. $\left(\mu \mathrm{A} \mathrm{cm}{ }^{-2}\right)$} \\
\hline \multirow{2}{*}{ no inh } & $1.5 \mathrm{~h}$ & 1.58 & 0.12 & 0.059 & 0.084 & 15.1 & 1.1 \\
& $24 \mathrm{~h}$ & 0.93 & 0.11 & 0.11 & 1.2 & 46.8 & 10.2 \\
inh & $1.5 \mathrm{~h}$ & 1.57 & 0.90 & 0.045 & 0.21 & 16.9
\end{tabular}

In order to be able to compare these LPR results with the results obtained through PP measurements earlier, the $\mathrm{i}_{\text {corr }}$ is calculated from the $R_{p}$ and the anodic and cathodic slopes of the Tafel plot $\left(\beta_{\mathrm{a}}\right.$ and $\beta_{\mathrm{c}}$, respectively) according to the Stern-Geary equation: ${ }^{13}$

$$
i_{\text {corr }}=\frac{\beta_{a} \cdot \beta_{c}}{2.3\left(\beta_{a}+\beta_{c}\right) R_{p}}
$$

For comparison, an LPR value after 1.5 hours is calculated as the average from the $R_{p}$ values after 1 and 2 hours, respectively. The necessary parameters for the calculation of $i_{\text {corr }}$ are summarized in Table II. It can be seen that the resulting $i_{\text {corr }}$ values are $15.1 \pm 1.1 \mu \mathrm{A}$ $\mathrm{cm}^{2}$ and $46.8 \pm 5.5 \mu \mathrm{A} \mathrm{cm}{ }^{2}$ for the hot-dip galvanized steel without corrosion inhibitors and $10.2 \pm 5.8 \mu \mathrm{A} \mathrm{cm} \mathrm{cm}^{2}$ and $16.9 \pm 1.5 \mu \mathrm{A} \mathrm{cm}$ for the hot-dip galvanized steel with $0.5 \mathrm{mM}$ of corrosion inhibitor in $0.05 \mathrm{M} \mathrm{NaCl}$, after 1.5 hours and 24 hours respectively.

Comparison of these $i_{\text {corr }}$ values with the previously obtained $i_{\text {corr }}$ values through PP measurement reveals that there is a good agreement between the values after 1.5 hours for both the system without and with corrosion inhibitor, although the standard deviation on the latter is considerable. In the case of the results after 24 hours, a remarkable difference can be observed in both cases. However, it is important to remark that for the determination of $i_{\text {corr }}$ from LPR using SternGeary, values determined from the Tafel extrapolation need to be used, making an independent comparison impossible.
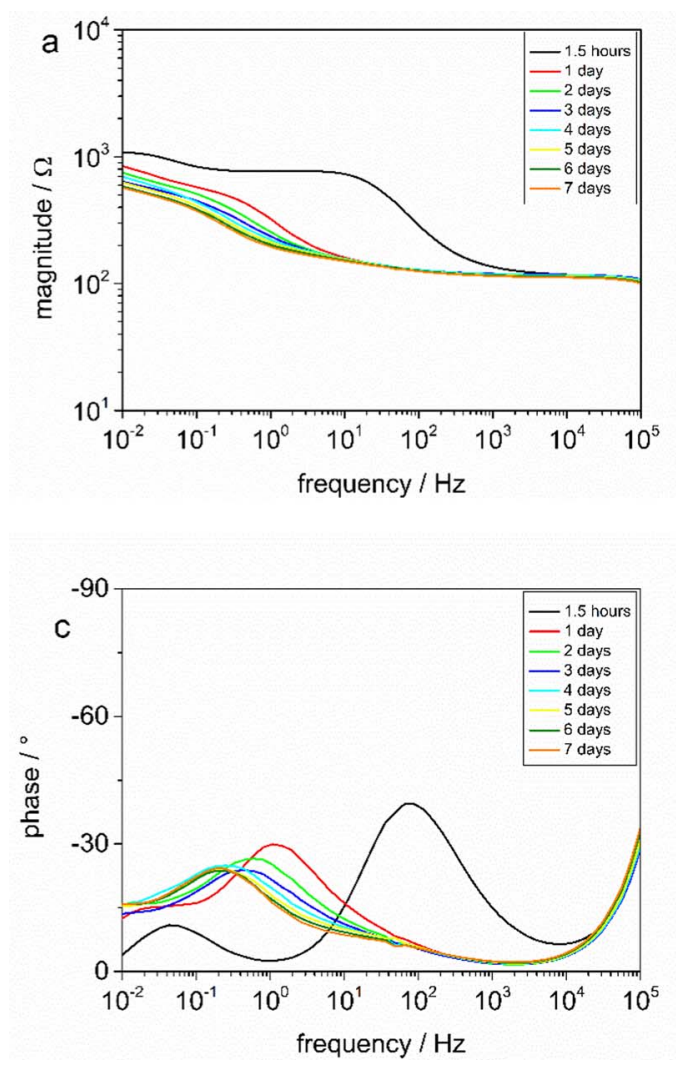

It has been shown that the application of OCP with superimposed LPR measurements with a small amplitude of the excitation signal every hour allows multiple measurements on the same sample over time to be performed. Consequently, they present a faster, non-invasive alternative to the PP technique, although, any mechanistic information about the cathodic and anodic behavior is lost.

Electrochemical impedance spectroscopy. - The electrochemical characteristics of the hot-dip galvanized steel with and without corrosion inhibitor were evaluated with EIS. Figure 3 shows the Bode plots of the different systems every day up to 1 week after immersion. The Bode plots of the hot-dip galvanized steel without corrosion inhibitor (Fig. 3a) show a remarkable decrease in the impedance modulus of the middle frequency $\left(10^{3}-10^{0} \mathrm{~Hz}\right)$ and a gradual decrease in the low frequency $\left(10^{0}-10^{-1} \mathrm{~Hz}\right)$ region over time. The associated phase plot clearly shows two time-constants, one in the middle frequency region and one in the lower frequency region. The former is associated with corrosion activity, related to the effect of the ionic double layer capacitance. ${ }^{47,48}$ The latter is related to the diffusion of the zinc oxidation products to the bulk solution or to oxygen reduction. ${ }^{11,48-50}$ Associated with the decrease in impedance modulus in mid- and lowfrequency regions is a decrease and shift of the phase angle of the first time-constant toward lower frequencies and a decrease of the phase angle of the second time-constant. This can be related to the decreased corrosion resistance of the reference system.
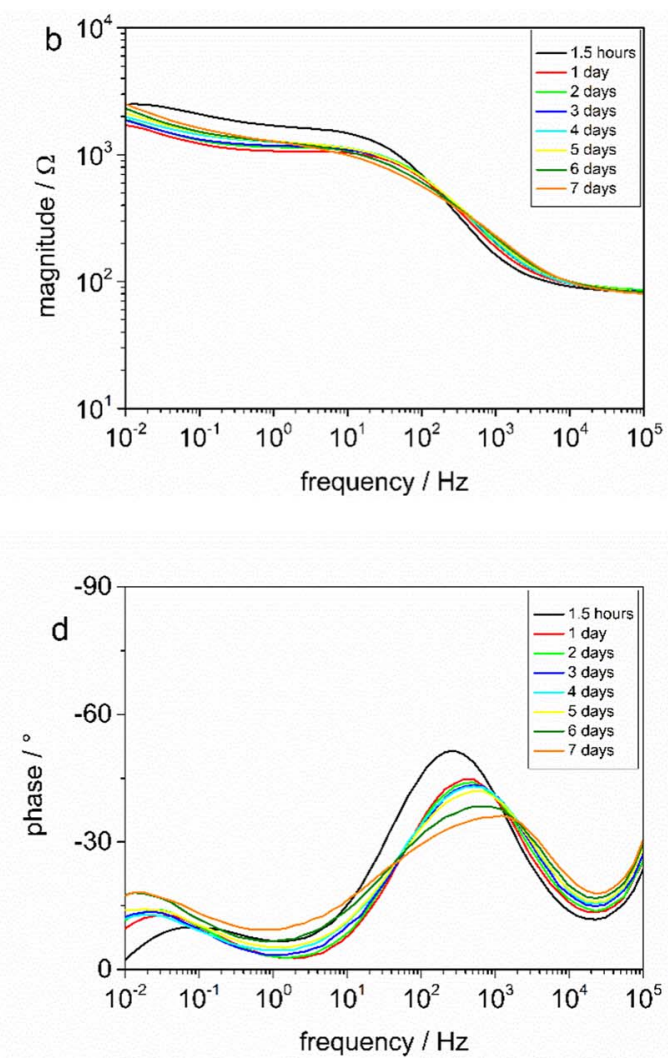

Figure 3. EIS Bode plots for hot-dip galvanized steel (a,c) without corrosion inhibitor $(0.05 \mathrm{M} \mathrm{NaCl})$ and $(\mathrm{b}, \mathrm{d})$ with corrosion inhibitor $(0.5 \mathrm{mM}$ Heucophos CAPP) every $24 \mathrm{~h}$ for $168 \mathrm{~h}$. 


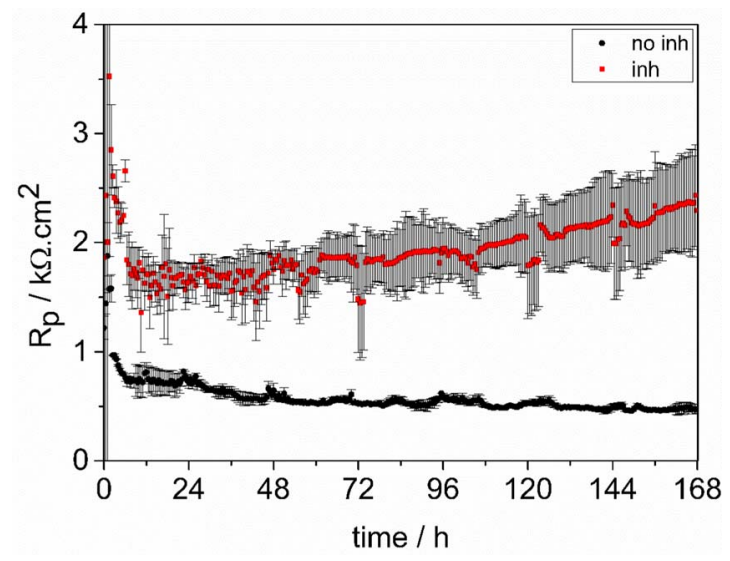

Figure 4. Polarization resistance $\left(\mathrm{R}_{\mathrm{p}}\right)$ results and their standard deviation obtained from electrochemical impedance spectroscopy measurements of hot-dip galvanized steel without $(0.05 \mathrm{M} \mathrm{NaCl})$ and with corrosion inhibitor $(0.5 \mathrm{mM}$ Heucophos CAPP) for $168 \mathrm{~h}$.

The Bode plots of the hot-dip galvanized steel with corrosion inhibitor (Fig. 3b) show an initial decrease in the magnitude of the impedance modulus at $10 \mathrm{mHz}$ during the first day of immersion. Afterwards the magnitude of the impedance modulus increases again over time. The Bode phase plot reveals again two time-constants. The first time-constant, in the mid-frequency region, decreases slightly with time, but shifts to higher frequencies, revealing the occurrence of corrosion protective action on the surface. The second time-constant, in the low-frequency region, increases over the course of 168 hours, indicating an increased corrosion protection. ${ }^{17,51}$

To evaluate the consistency between the results obtained from different electrochemical techniques, the $\mathrm{R}_{\mathrm{p}}$ values of the EIS measurements are calculated. For the LPR measurements, the $R_{p}$ values were directly available, while for the EIS measurements the $R_{p}$ values can be determined from the real component of the impedance at $100 \mathrm{kHz}$ and $10 \mathrm{mHz}$ according to. ${ }^{52}$

$$
R_{p}=Z^{\prime}(0)-Z^{\prime}(\infty)
$$

Figure 4 shows the evolution of the $\mathrm{R}_{\mathrm{p}}$ with their standard deviation obtained from EIS measurements for the system with and without corrosion inhibitor as a function of immersion time. It can be seen that, for the system without corrosion inhibitors, the $R_{p}$ is $1.87 \pm$ $0.31 \mathrm{k} \Omega \mathrm{cm}^{2}$ after 1 hour and decreases strongly in the initial hours after immersion. After 10 hours, a $R_{p}$ value of $0.75 \pm 0.13 \mathrm{k} \Omega \mathrm{cm}^{2}$ is reached. Subsequently, the $\mathrm{R}_{\mathrm{p}}$ decreases more slowly, reaching a value of $0.475 \pm 0.041 \mathrm{k} \Omega \mathrm{cm}^{2}$ after 168 hours.

The $R_{p}$ of hot-dip galvanized steel with corrosion inhibitor is $2.85 \pm$ $0.42 \mathrm{k} \Omega \mathrm{cm}^{2}$ after 2 hours of immersion and decreases rapidly in the first 12 hours after immersion, reaching a value of $1.71 \pm 0.16 \mathrm{k} \Omega \mathrm{cm}^{2}$. Afterwards, the $R_{p}$ value starts increasing gradually with time for the remaining duration of the measurement. After 168 hours of immersion, the $R_{p}$ value has reached a value of $2.43 \pm 0.47 \mathrm{k} \Omega \mathrm{cm}^{2}$.

The $R_{p}$ values of the hot-dip galvanized steel without corrosion inhibitor in this work are similar to the results obtained by Kartsonakis et al. ${ }^{11} \mathrm{R}_{\mathrm{p}}$ values of $0.77,0.63$ and $0.86 \mathrm{k} \Omega \mathrm{cm}^{2}$ were obtained after $3 \mathrm{~h}, 72 \mathrm{~h}$ and $168 \mathrm{~h}$ in $0.05 \mathrm{M} \mathrm{NaCl}$, while values of $0.969 \pm 0.011$, $0.524 \pm 0.012$ and $0.475 \pm 0.041 \mathrm{k} \Omega \mathrm{cm}^{2}$ were obtained in this work. A comparison with the $R_{p}$ values obtained from LPR measurements will be made at a later stage.

It has been demonstrated that EIS measurements provide both qualitative and quantitative information about the performance of the electrochemical system over time. Compared to PP and OCP with superimposed LPR measurements, EIS provides also frequency-resolved information about the corrosion inhibition mechanism, related to the presence of different time-constants, while assumingly working in the stationary regime of the electrochemical process.

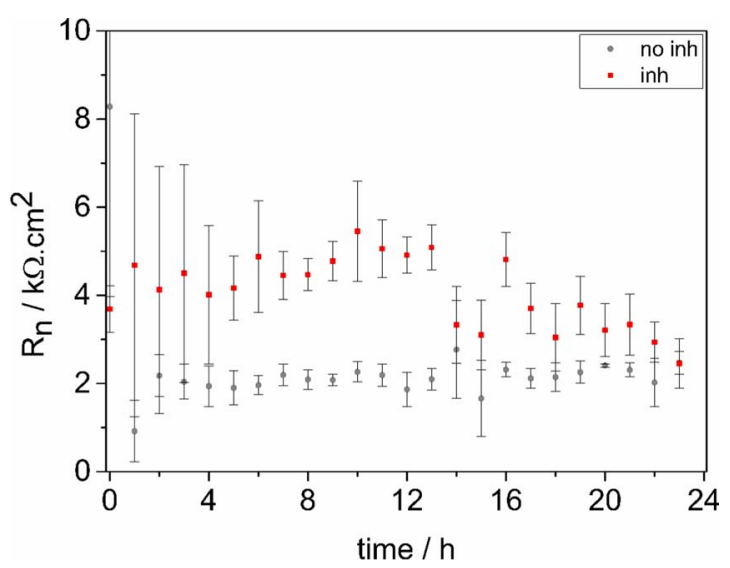

Figure 5. Noise resistance $\left(R_{n}\right)$ results and their standard deviation obtained from electrochemical noise measurements of hot-dip galvanized steel without $(0.05 \mathrm{M} \mathrm{NaCl})$ and with corrosion inhibitor $(0.5 \mathrm{mM}$ Heucophos CAPP) in the first $24 \mathrm{~h}$ after immersion.

Electrochemical noise measurements.-EN measurements were carried out continuously for 24 hours after immersing the hot-dip galvanized steel in the electrolyte with or without corrosion inhibitor. In order to make a useful comparison with other stationary and nonstationary electrochemical techniques, the electrochemical potential (EPN) and current noise (ECN) are divided into windows of 1 hour. For each of these windows the DC drift component is removed through a discrete wavelet transform (DWT) procedure. ${ }^{42}$ The noise resistance $\left(R_{n}\right)$ is then calculated by dividing the standard deviation of the EPN by the standard deviation of the ECN according to: ${ }^{.3}$

$$
R_{n}=\frac{s t d(E P N)}{s t d(E C N)}
$$

Afterwards, the $\mathrm{R}_{\mathrm{n}}$ is normalized by the area of the working electrode, $0.28 \mathrm{~cm}^{2}$ in this case. ${ }^{54}$ This electrochemical quantity is selected because of its equivalence to the polarization resistance $R_{p} .{ }^{55}$ In Figure 5, the $R_{n}$ of the hot-dip galvanized steel with and without corrosion inhibitor in the first 24 hours after immersion is presented. The time indicated corresponds to the starting time of each respective window. It can be seen that the $R_{n}$ and its standard deviation is $8.3 \pm 4.3 \mathrm{k} \Omega \mathrm{cm}^{2}$ and $3.68 \pm 0.53 \mathrm{k} \Omega \mathrm{cm}^{2}$ right after immersion for the system without and with corrosion inhibitors, respectively. The $\mathrm{R}_{\mathrm{n}}$ of the hot-dip galvanized steel without corrosion inhibitors after 2 hours of immersion is $2.18 \pm 0.47 \mathrm{k} \Omega \mathrm{cm}^{2}$ and remains just at around $2 \mathrm{k} \Omega \mathrm{cm}^{2}$ for the rest of the measurement. In the case of the hot-dip galvanized steel with corrosion inhibitor, the $\mathrm{R}_{\mathrm{n}}$ increases gradually toward $5.5 \pm 1.1 \mathrm{k} \Omega$ $\mathrm{cm}^{2}$ after 10 hours of immersion before decreasing again to reach a value of $2.45 \pm 0.56 \mathrm{k} \Omega \mathrm{cm}^{2}$ after 24 hours of immersion, comparable to what is obtained for the system without corrosion inhibitor.

It can be concluded that EN measurements can quantitatively describe the electrochemical system in terms of the $R_{n}$, averaged over a specific time frame. Additionally, EN measurements are able to present non-stationary information, while the previous techniques assumingly work in a stationary regime.

Odd-random-phase electrochemical impedance spectroscopy measurements.-Qualitative interpretation of ORP-EIS noise distortions. - In order to examine the evolution of the system toward a 'stable' electrochemical system, i.e. meeting the three requirements needed for a valid EIS spectrum, ${ }^{20}$ both hot-dip galvanized steel with and without corrosion inhibitor were intensively monitored (a measurement was performed every 15 minutes) for 24 hours after immersion in the electrolyte. In Figure 6, the ORP-EIS results of the hot-dip galvanized steel after $15 \mathrm{~min}, 1 \mathrm{~h}, 2 \mathrm{~h}, 5 \mathrm{~h}, 8 \mathrm{~h}$ and $10 \mathrm{~h}$ in $0.05 \mathrm{M}$ $\mathrm{NaCl}$ are presented. The black line and the gray line represent the magnitude of the impedance modulus, labelled as 'experiment', and the phase angle, respectively. The characteristics of the ORP-EIS data 

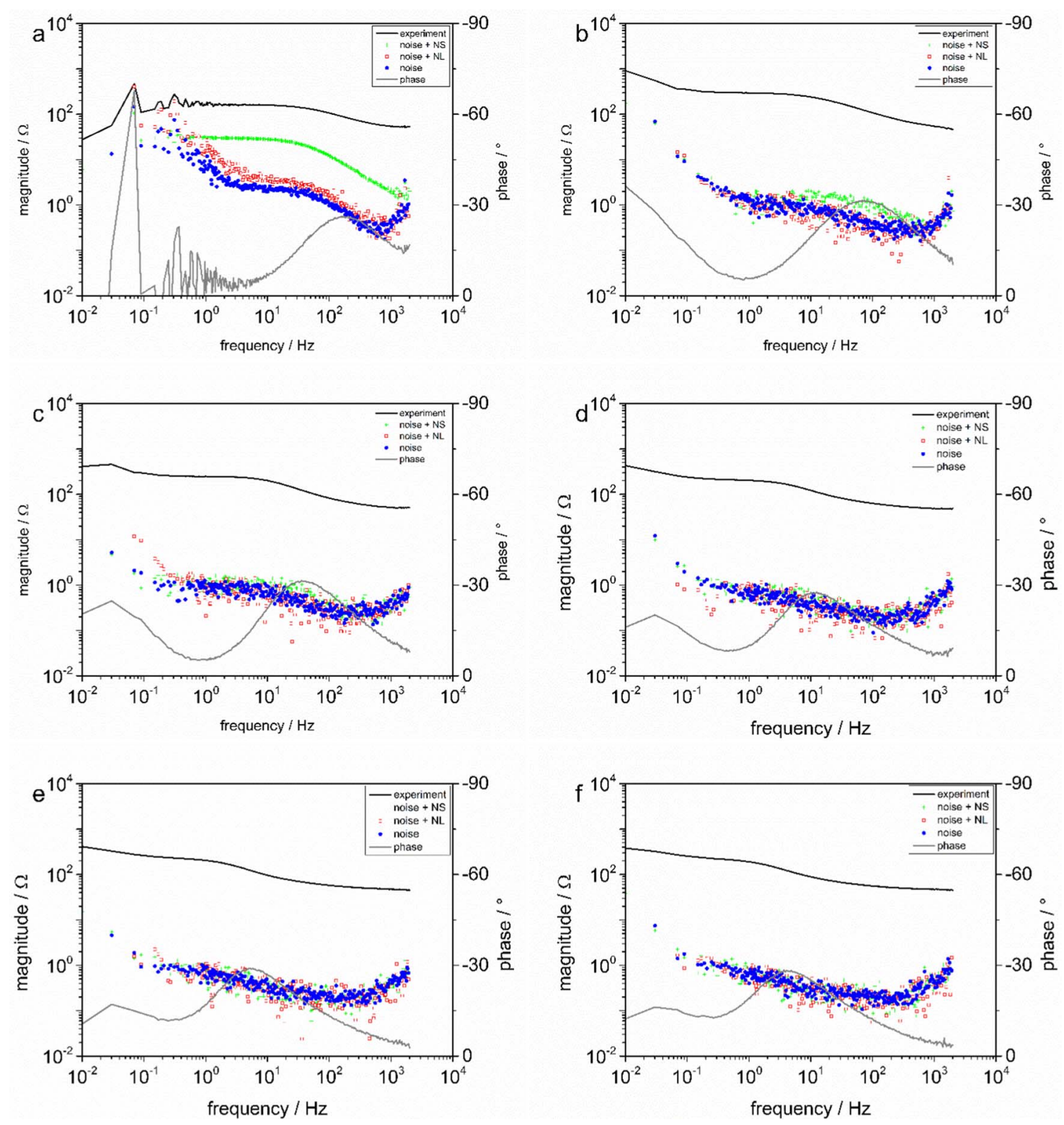

Figure 6. Bode plots of hot-dip galvanized steel without corrosion inhibitor after $15 \mathrm{~min}$ (a), $1 \mathrm{~h} \mathrm{(b),} 2 \mathrm{~h} \mathrm{(c),} 5 \mathrm{~h}$ (d), $8 \mathrm{~h}$ (e) and $10 \mathrm{~h}$ (f) in $0.05 \mathrm{M} \mathrm{NaCl}$ with the experimental impedance and noise distortion curves.

are presented by the curves representing the noise, the noise plus the non-linearities (NL) and the noise plus the non-stationarities (NS). The ORP-EIS data interpretation can be described in the following way: in order to have a fully linear system, the noise curve and the noise + non-linearities curve have to overlap, indicated by an equal amount of points above and under the noise curve; in order to have a fully time-invariant system, the noise and noise + non-stationarities curve have to overlap. ${ }^{25,31}$

For the hot-dip galvanized steel after $15 \mathrm{~min}$ in the reference electrolyte (Fig. 6a), neither the noise + non-linearities nor the noise + non-stationarities overlaps the noise curve. This indicates the presence of non-linearities and non-stationarities in the system. After 1 hour of immersion (Fig. 6b), the noise + non-linearities curve overlaps with the noise curve, suggesting the system has evolved toward a linear system. Nevertheless, the noise + non-stationarities curve does not overlap with the noise curve in the middle and higher frequency regions $\left(10^{0}-10^{3} \mathrm{~Hz}\right)$, meaning that the overall system is still behaving in a non-stationary way because the electrochemical processes with characteristic time-constants corresponding to the middle and high frequency regions are still 'unstable'. After 2 hours of im- mersion (Fig. 6c), the noise + non-stationarities curve overlaps the noise curve in the low frequency $\left(10^{-2}-10^{0} \mathrm{~Hz}\right)$ and high frequency $\left(10^{2}-2 \cdot 10^{3} \mathrm{~Hz}\right)$ regions indicating that the electrochemical processes with corresponding time-constants are behaving stable. However, the noise + non-stationarities curve is not overlapping the noise curve in the middle frequency region $\left(10^{0}-10^{2} \mathrm{~Hz}\right)$. After 5 hours of immersion (Fig. 6d), the noise + non-stationarities curve approaches the noise curve in the middle frequency region, almost fulfilling the condition of time-invariance. After 8 hours of immersion (Fig. 6e), the noise + non-stationarities curve also overlaps the middle frequency region from $10^{1}-10^{2} \mathrm{~Hz}$, but in the middle frequency region from $10^{0}$ $-10^{0} \mathrm{~Hz}$ the noise + non-stationarities curve is not completely overlapping the noise curve yet. After 10 hours of immersion (Fig. 6f) the noise + non-stationarities curve overlaps completely with the noise curve and the system is behaving fully linearly and stationary.

Comparison of the situation after 1.5 hours from EIS (Fig. 3a and Fig. 3c) with the situation after 1 hour and 2 hours from ORP-EIS (Fig. 6b and Fig. 6c) shows good agreement in the phase angle plots in terms of the number of time-constants and the shape and position of the respective time-constants. The same goes for the magnitude of 

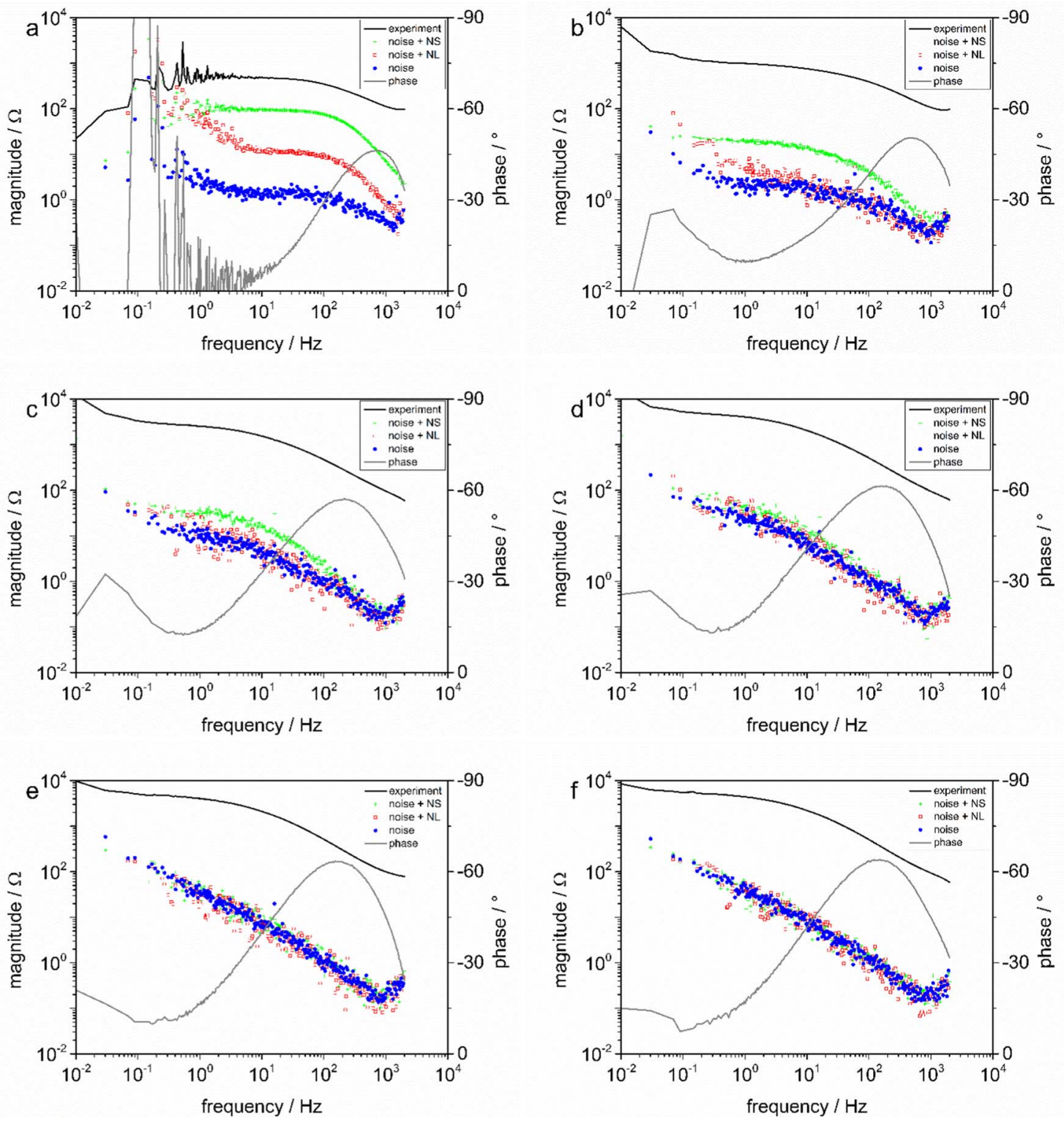

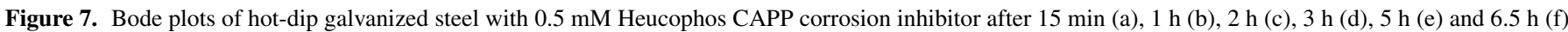
with the experimental impedance and noise distortion curves.

the impedance modulus plots apart from the low-frequency behavior, however, difficult to observe because of the log-log scale. This can be explained as follow: any discrepancies between the values from point to point observed from EIS and ORP-EIS in the magnitude of the impedance modulus need to be interpreted taking into account the contribution of the noise, the non-linearities and non-stationarities on these points. ${ }^{25}$ The contribution of these noise distortions are correcting for any non-linear and non-stationary behavior. In this case, only the contribution of the noise and the non-stationarities has to be taken into account since it has been shown that the system without corrosion inhibitor behaves in a non-stationary way at these times.

In Figure 7, the Bode plots of hot-dip galvanized steel with corrosion inhibitor are presented. After 15 minutes of immersion in the electrolyte (Fig. 7a), neither the noise + non-linearities curve nor the noise + non-stationarities curve completely overlaps the noise curve, indicating that the system did not reach the linearity and stationarity condition yet. After 1 hour of immersion, the noise + non-linearities curve overlaps the noise curve in the high frequency region and starts overlapping the noise curve in the middle and low frequency region. The noise + non-stationarities curve does not overlap the noise curve.
Overall the system is still behaving in a non-linear and non-stationary way. After 2 hours of immersion (Fig. 7c), the noise + non-linearities completely overlaps the noise curve, indicating that the system has fulfilled the linearity condition. At the same time, the noise + nonstationarities curve starts approaching the noise curve in the high frequency $\left(10^{2}-2 \cdot 10^{3} \mathrm{~Hz}\right)$ region but not yet in the low frequency $\left(10^{-2}-\right.$ $\left.10^{0} \mathrm{~Hz}\right)$ and middle frequency $\left(10^{0}-10^{2} \mathrm{~Hz}\right)$ regions. After 3 hours of immersion (Fig. 7d), the noise + non-stationarities further approaches the noise curve over the entire frequency range, almost fulfilling the stationarity condition. After 5 hours of immersion (Fig. 7e), the noise + non-stationarities completely overlaps the noise curve in the low frequency $\left(10^{-2}-10^{0} \mathrm{~Hz}\right)$ and high frequency $\left(10^{2}-2 \cdot 10^{3} \mathrm{~Hz}\right)$ regions, indicating that the electrochemical processes with characteristic time-constants corresponding to the low and high frequency region are stable and that, equivalently, the electrochemical processes with characteristic time-constants corresponding to the middle frequency region are 'unstable' and cause the overall system's instability. After 6.5 hours of immersion (Fig. 7f), both the noise + non-linearities curve and the noise + non-stationarities curve overlap the noise curve, meaning that the system behaves in a fully linear and stationary way. 
Similarly to the system without corrosion inhibitor, a comparison between the results from EIS after 1.5 hours (Fig. 3b and Fig. 3d) and ORP-EIS after 1 hour and 2 hours (Fig. 7b and Fig. 7c) can be made for the system with corrosion inhibitor. Here again, the phase angle plots show good agreement in terms of the number of time-constants and the shape and position of these time-constants and apart from the low frequency region, also the magnitude of the Bode impedance plots show good agreement. These discrepancies can again be explained by the presence of non-stationarities.

This qualitative interpretation signifies that for the system without and with corrosion inhibitor, it takes 10 hours and 6.5 hours respectively, to reach a stationary behavior and to fulfil the time-invariance condition. These periods of time correspond to the duration to reach a stable electrochemical process and designate the time the system needs to stabilize enabling a reliable EIS measurement to be obtained. The frequency dependent non-stationary behavior requires further investigation in terms of a quantitative interpretation of the non-linear and non-stationary noise distortions.

Quantitative interpretation of ORP-EIS noise data.-The qualitative interpretation of the ORP-EIS noise distortions data for the hot-dip galvanized steel with and without corrosion inhibitor presents an idea of the 'stabilization time' the respective system requires to meet the requirements of linearity and time-invariance. However, in order to draw a parallel between the morphological changes, the stability of electrochemical processes and the parameter evolution of the electrochemical parameters describing the electrochemical processes, the ORP-EIS information concerning the noise, non-linearities and non-stationarities present in the system is quantified. ${ }^{25}$

By numerical integration through interpolation over the frequency domain using the trapezoidal rule, and subtraction of the noise curve from the noise + non-linearities curve and noise + non-stationarities curve, the individual contributions of the noise, non-linearities and non-stationarities were calculated. ${ }^{56}$ Expressing this information relative to the magnitude of the impedance modulus (N/|Z|; NL/|Z|; $\mathrm{NS} / \mathrm{Z} \mid$ ), also quantified by a numerical integration through interpolation, yields the relative contribution of the noise, non-stationarities and non-linearities as a function of immersion time. In Figure 8, the curves representing the relative contribution of the noise, non-linearities and non-stationarities as a function of immersion time are presented for hot-dip galvanized steel with and without corrosion inhibitor.

For the hot-dip galvanized steel without corrosion inhibitors (Fig. 8a), it can be noticed that the non-stationarities have the highest relative contribution of the three right at the start after immersion in the electrolyte, with a relative contribution only more than one order of magnitude lower than the magnitude of the impedance modulus, corresponding to $4.89 \%$. The contribution of the noise is two orders of magnitude lower compared to the magnitude of the impedance modulus, corresponding to $1.03 \%$, and the contribution of the non-linearities more than two orders, accounting for only $0.17 \%$.

In the following hours, the contribution of the non-stationarities decreases over time. The relative contribution of the noise and the non-linearities remains equal over the course of the measurement. The contribution of the non-stationarities decreases strongly in the first hour, reaching a relative contribution of $3 \cdot 10^{-4}$ or less (Fig. 8a). Afterwards, the relative contribution of the non-stationarities keeps decreasing and after $2 \mathrm{~h}$, the contribution reaches a stable value of approximately $2 \cdot 10^{-4}$. This contribution remains stable for the rest of the measurement time.

It needs to be noted that this does not correspond completely with what was observed during the qualitative interpretation at longer times where a non-stationary behavior in the mid frequency regions was observed for 8 up to 10 hours. For that reason, and to examine the contribution of the different electrochemical processes to the overall system instability, the data regarding the non-stationarities was also quantified per frequency decade. ${ }^{25}$ Therefore, the impedance data were divided into 6 frequency decades. The first frequency decade, ranging from $10 \mathrm{mHz}$ to $100 \mathrm{mHz}$, and the last frequency decade, ranging from $1 \mathrm{kHz}$ to $10 \mathrm{kHz}$, were not taken into account because the former only
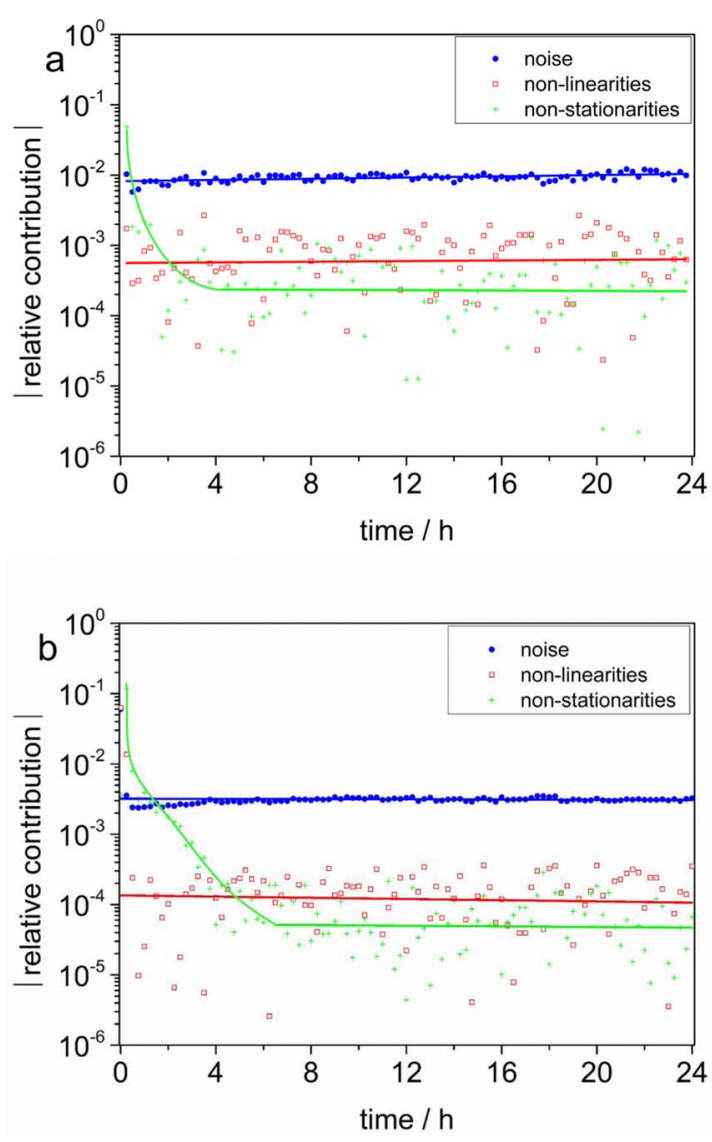

Figure 8. Evolution of the contribution of the noise, non-linearities and nonstationarities relative to the impedance modulus for hot-dip galvanized steel (a) without corrosion inhibitor $(0.05 \mathrm{M} \mathrm{NaCl})$ and (b) with corrosion inhibitor ( $0.5 \mathrm{mM}$ Heucophos CAPP) for the first $24 \mathrm{~h}$ of immersion, respectively. The blue, red and green line represent the trend line of the noise, non-linearities and non-stationarities, respectively.

contains three data points and the latter comprises only data of one tenth of the frequency decade. The relative contributions (NS/|Z|) are calculated for each frequency decade and presented in Figure 9.

It can be observed that the contribution of the non-stationarities (Fig. 9a) decreases for every frequency decade with time. For the lowest and highest frequency decades (II and V), ranging from $10^{-1} \mathrm{~Hz}$ to $10^{0} \mathrm{~Hz}$ and from $10^{2} \mathrm{~Hz}$ to $10^{3} \mathrm{~Hz}$, respectively, the contribution decreases more rapidly and stabilizes after 2 hours. For the middle frequency decades (III and IV), ranging from $10^{0} \mathrm{~Hz}$ to $10^{1} \mathrm{~Hz}$ and from $10^{1} \mathrm{~Hz}$ to $10^{2} \mathrm{~Hz}$, respectively,the contribution decreases more slowly and stabilizes only after 10 hours and 8 hours, respectively. Therefore the system needs to be considered as a non-stationary system for the first 10 hours.

It needs to be remarked that the non-stationarities observed in the qualitative interpretation were not reflected in the overall quantitative interpretation but only in the quantitative interpretation per decade. Consequently, when studying the evolution of an electrochemical system, and in particular the stabilization of different electrochemical processes with different characteristic time-constants, it is important to consider the quantitative interpretation per frequency decade.

For the hot-dip galvanized steel with corrosion inhibitor, it can be observed from the quantitative interpretation (Fig. 8b) that the relative contribution of the noise and non-linearities are the highest right after the start of immersion, only 1 order of magnitude lower compared to the magnitude of the impedance modulus, corresponding to $6.02 \%$ and $6.30 \%$, respectively. All three contributions decrease over time. The relative contribution of the noise decreases to $3 \cdot 10^{-3}$ after 30 minutes of immersion and remains stable for the rest of the measurement. 

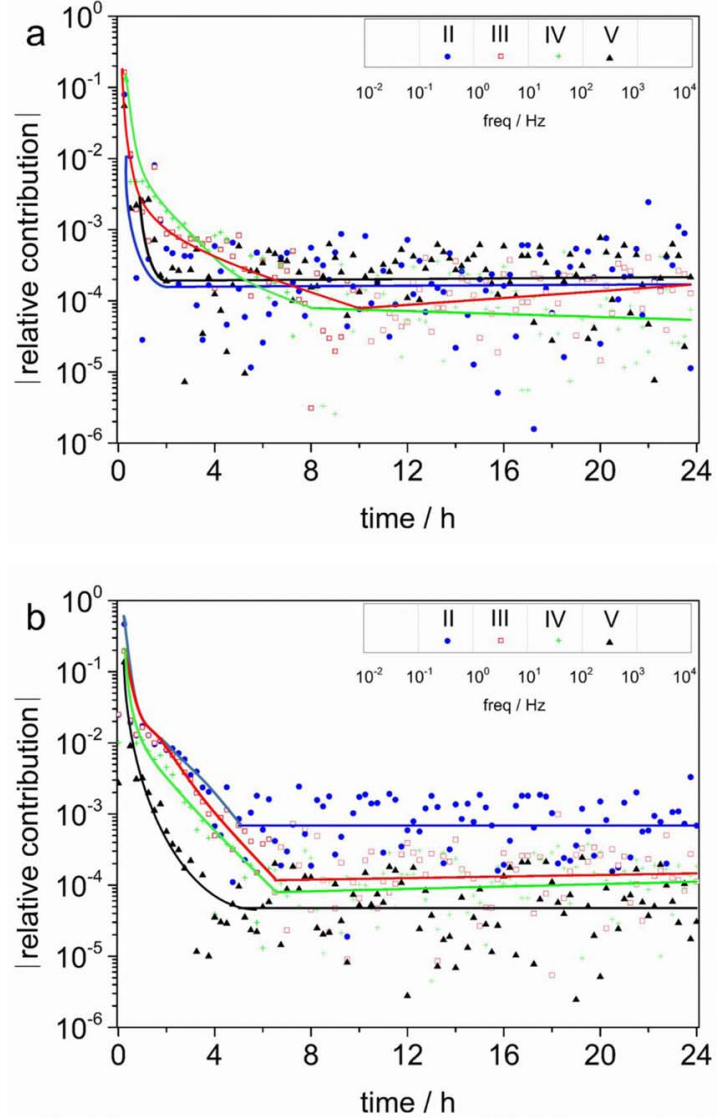

Figure 9. Evolution of the relative contribution of the non-stationarities for the different frequency decades for hot-dip galvanized steel (a) without corrosion inhibitor $(0.05 \mathrm{M} \mathrm{NaCl})$ and $(\mathrm{b})$ with corrosion inhibitor $(0.5 \mathrm{mM}$ Heucophos CAPP) for the first $24 \mathrm{~h}$ of immersion, respectively. The blue, red, green and black lines represent the trend line of the non-stationarities in the respective frequency decades.

The contribution of the non-linearities decreases rapidly in the first 30 minutes and reaches a value of $3 \cdot 10^{-4}$ or less which remains the same for the rest of the measurement. The contribution of the nonstationarities decreases more gradually. After 1 hour of immersion, the relative contribution is around $4 \cdot 10^{-3}$, after 2 hours around $2 \cdot 10^{-3}$ and after 3 hours around $8 \cdot 10^{-4}$. Only after 6.5 hours, the relative contribution of the non-stationarities stabilizes around $2 \cdot 10^{-4}$ or less, indicating a fully stationary electrochemical system.

Similarly to the hot-dip galvanized steel without corrosion inhibitor, the same quantification per decade was carried out for the system with corrosion inhibitor. From the quantification of the nonstationarities per decade (Fig. 9b), it can be seen that the contribution of the non-stationarities decreases with time for all frequency decades.

The relative contribution the non-stationarities of the lowest (II) and highest $(\mathrm{V})$ frequency decades decrease more rapidly and reach a stable value after 5 hours. The relative contribution of the nonstationarities of the middle frequency (III and IV) region decrease more slowly and stabilize after 6.5 hours of immersion. This trend is in good agreement with what was observed earlier in a qualitative and quantitative way, with a higher non-stationary behavior in the mid frequency region. This indicates that the electrochemical processes with characteristic time-constants corresponding to the mid frequency region take the longest time to stabilize and dominate the overall instability of the electrochemical system.

Here it can be concluded that the qualitative behavior of the nonstationarities is reflected in both the overall quantitative interpretation and the quantitative interpretation per decade. Moreover, it can be
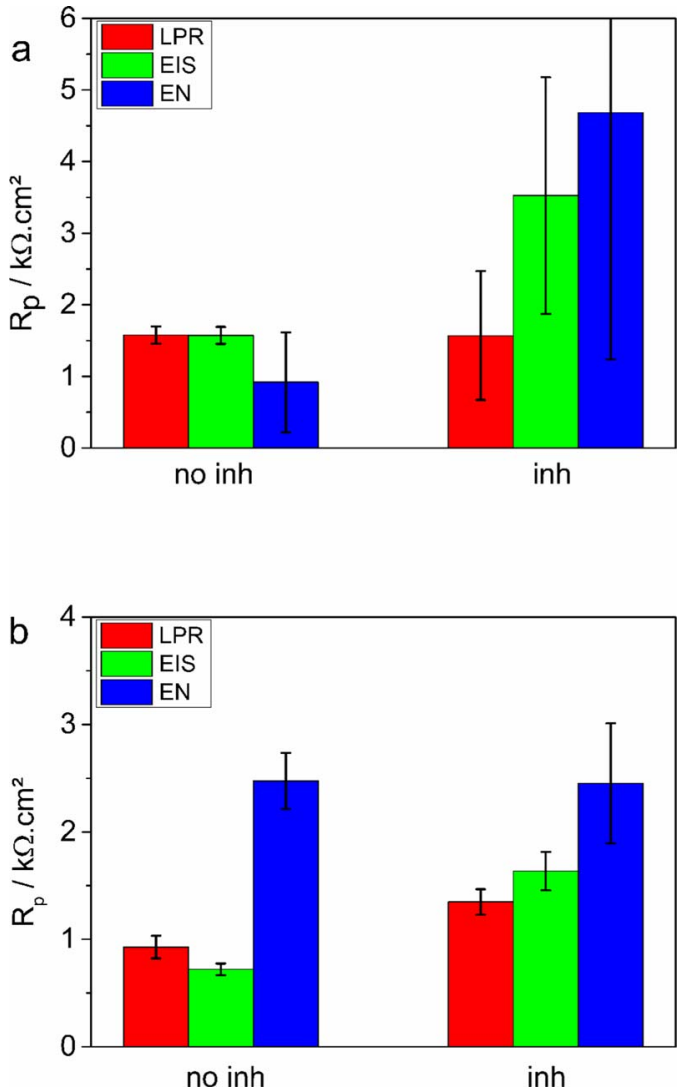

Figure 10. Overview of the results obtained through linear polarization resistance (LPR), electrochemical impedance spectroscopy (EIS) and electrochemical noise (EN) measurements for hot-dip galvanized steel without $(0.05 \mathrm{M}$ $\mathrm{NaCl}$ ) and with corrosion inhibitor (0.5 mM Heucophos CAPP) after (a) $1.5 \mathrm{~h}$ and (b) $24 \mathrm{~h}$.

concluded that ORP-EIS measurements are able to detect and quantify stationary and non-stationary behavior of electrochemical processes and consequently describe the stability of an electrochemical system over time.

Overview of the electrochemical results after 1.5 hours and 24 hours.-The objective of this work was to compare the results obtained from different macroscopic electrochemical techniques. Before discussing the overall behavior over time, we can discuss the results obtained after 1.5 hours and 24 hours, since a PP measurement was only performed at these two times. For comparison reasons, a LPR value after 1.5 hours is calculated as the average from the polarization resistance values after 1 and 2 hours, respectively, and the noise resistance of the noise measurements between 1 hour and 2 hours is selected. In Figure 10, the $R_{p}$ obtained from LPR, EIS and EN measurements after 1.5 hours and 24 hours is presented, as well as the absolute errors in the respective resistances.

It can be seen that for the hot-dip galvanized steel after 1.5 hours (Fig. 10a), the $R_{p}$ values obtained from LPR, EIS and EN measurements are $1.58 \pm 0.12 \mathrm{k} \Omega \mathrm{cm}^{2}, 1.57 \pm 0.12 \mathrm{k} \Omega \mathrm{cm}^{2}$ and $0.92 \pm$ $0.70 \mathrm{k} \Omega \mathrm{cm}^{2}$, respectively. For the hot-dip galvanized steel with corrosion inhibitor after 1.5 hours, the $\mathrm{R}_{\mathrm{p}}$ values are $1.57 \pm 0.90 \mathrm{k} \Omega \mathrm{cm}^{2}$, $3.5 \pm 1.7 \mathrm{k} \Omega \mathrm{cm}^{2}$ and $4.7 \pm 3.4 \mathrm{k} \Omega \mathrm{cm}^{2}$, respectively.

For the hot-dip galvanized steel after 24 hours (Fig. 10b), the $R_{p}$ values obtained from LPR, EIS and EN measurements are $0.93 \pm 0.11$ $\mathrm{k} \Omega \mathrm{cm}^{2}, 0.720 \pm 0.053 \mathrm{k} \Omega \mathrm{cm}^{2}$ and $2.47 \pm 0.26 \mathrm{k} \Omega \mathrm{cm}^{2}$, respectively. In the case of hot-dip galvanized steel with corrosion inhibitor, the $\mathrm{R}_{\mathrm{p}}$ values are $1.35 \pm 0.12 \mathrm{k} \Omega \mathrm{cm}^{2}, 1.63 \pm 0.18 \mathrm{k} \Omega \mathrm{cm}^{2}$ and $2.45 \pm$ $0.56 \mathrm{k} \Omega \mathrm{cm}^{2}$, respectively. 
First of all, it needs to be remarked that the errors on the EN measurements are significantly high, especially for the measurements after 1.5 hours. For the other two electrochemical techniques, all errors are below $15 \%$, except for the $R_{p}$ values obtained from LPR and EIS measurements after 1.5 hours, which are $57 \%$ and $47 \%$ respectively. It has been observed that the results after 1.5 hours suffer from nonstationary behavior, causing an overall unstable electrochemical system after 1.5 hours, as observed from the ORP-EIS experiments. This is reflected in unstable $R_{p}$ values after relatively short immersion times. For the LPR and EIS technique, which assume stationarity during measurement, this is evident. For the EN technique, which measures non-stationarity behavior, the DWT procedure applied for DC drift removal suffers from the presence of non-stationarities. Despite the high effectiveness of this procedure, the effect of the non-stationarities is never eliminated completely, causing the spread of the first EN measurements. Also the uncertainty related to electrode asymmetry when performing an EN measurement is worth mentioning, since this is not applicable for an LPR or EIS measurement and could lead to misinterpretation of the EN data. This has already led to the conclusion that EIS provides a better estimate of the impedance than EN does. ${ }^{54}$

In general, the results obtained through LPR and EIS are more in line with each other than with the EN measurement results after similar immersion times. When interpreting the results obtained after 1.5 hours, it is important to consider that both the systems with and without corrosion inhibitor were still behaving in a non-stationary fashion. As a result, the basic conditions necessary for successful application of the EIS technique are not fulfilled, which is reflected in the large scatter of values.

In the case of EN measurements and the calculation of the noise resistance as a function of time, it needs to be remarked that the system is not polarized and as such the spontaneous corrosion process is measured. Any non-stationarity behavior in the corrosion process will manifest itself as DC drift in the EN signal, which has a large influence on the determination of standard deviation and, as a result, on the noise resistance. Consequently, the accuracy of the calculated noise resistance relies heavily on the effectiveness of the applied DC drift removal procedure. Although this is interesting from a scientific point of view, the different nature of the EN technique as compared to the active electrochemical techniques investigated in this paper makes comparison with the $\mathrm{R}_{\mathrm{p}}$ values from the other techniques rather difficult.

Overview of the electrochemical results over time.-In Figure 11, the $R_{p}$ values of the hot-dip galvanized steel with and without corrosion inhibitor obtained through LPR, EIS and EN measurements, together with the relative contribution of the non-stationarities from the ORP-EIS measurements over the course of 24 hours, are presented. The deviation of the $R_{p}$ obtained from EN measurements compared with the other electrochemical techniques was already discussed in the previous paragraph.

It can be seen that for the hot-dip galvanized steel without corrosion inhibitor (Fig. 11a) the $\mathrm{R}_{\mathrm{p}}$ values obtained from LPR and EIS measurements, measured every hour and every 30 minutes, respectively, show a similar trend over the course of the measurement. After 1 hour, the $R_{p}$ values obtained from LPR and EIS are $1.65 \pm 0.14 \mathrm{k} \Omega$ $\mathrm{cm}^{2}$ and $1.87 \pm 0.31 \mathrm{k} \Omega \mathrm{cm}^{2}$, respectively. Both decrease strongly in the first 10 hours, reaching a $R_{p}$ value of $0.99 \pm 0.12 \mathrm{k} \Omega \mathrm{cm}^{2}$ for the LPR and $0.75 \pm 0.13 \mathrm{k} \Omega \mathrm{cm}^{2}$ for the EIS measurement, respectively. Afterwards, the $R_{p}$ values remain stable. This time corresponds to the time needed until the system is fully stationary and can be considered as 'stable', as indicated by the gray lines representing the relative contribution of the non-stationarities of frequency decade III and IV. In the quantitative interpretation per decade, it has been observed that the electrochemical processes with characteristic time-constants corresponding to these frequency decades were the last to stabilize and cause the overall system instability during the first 10 hours after immersion.

After 10 hours, the electrochemical system is 'stable', since the relative contribution of the non-stationarities are minimal and remain
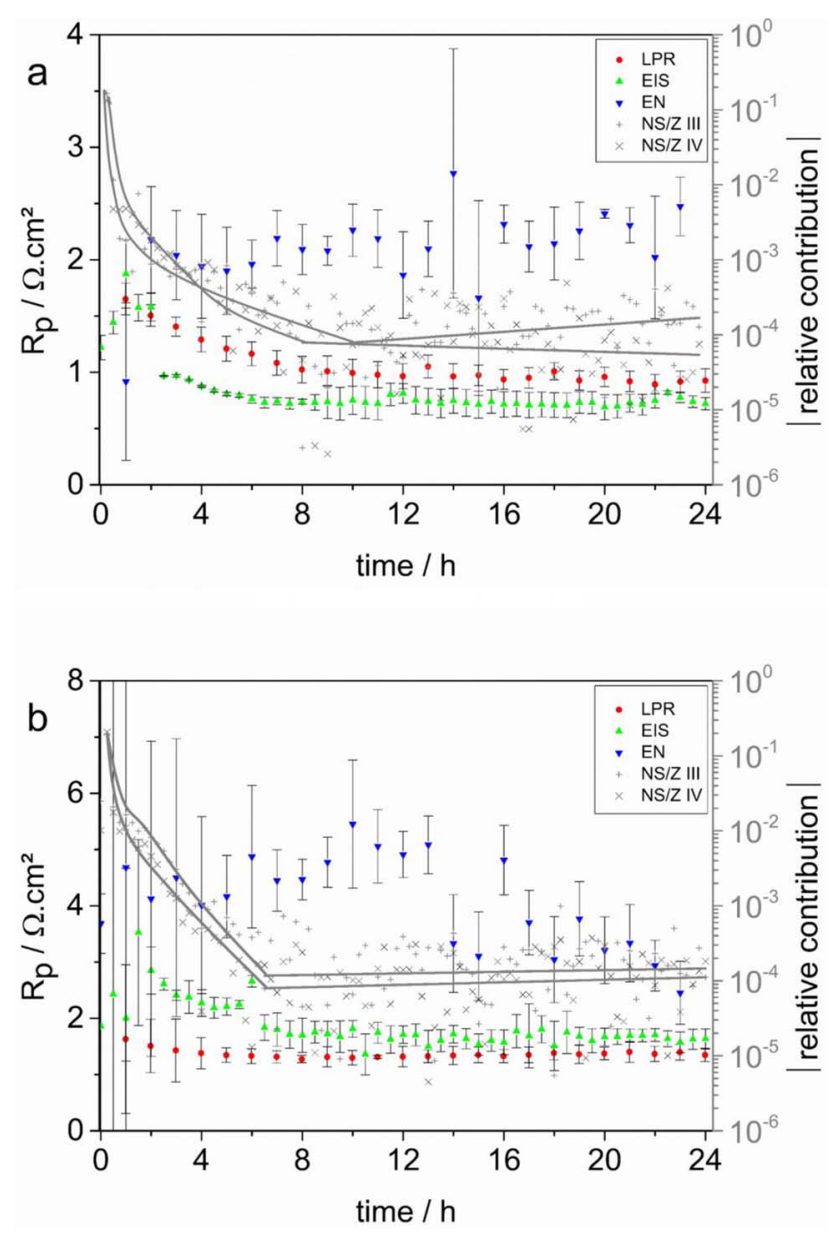

Figure 11. Overview of the results obtained through linear polarization resistance (LPR), electrochemical impedance spectroscopy (EIS), electrochemical noise (EN) and odd random phase electrochemical impedance spectroscopy (ORP-EIS) measurements for hot-dip galvanized steel (a) without corrosion inhibitor $(0.05 \mathrm{M} \mathrm{NaCl})$ and (b) with corrosion inhibitor $(0.5 \mathrm{mM}$ Heucophos CAPP) for $24 \mathrm{~h}$.

stable for the rest of the measurement. This is reflected in the stable $R_{p}$ values in the same timeframe.

In Figure $11 b$, the $\mathrm{R}_{\mathrm{p}}$ of the hot-dip galvanized steel with corrosion inhibitor obtained through LPR, EIS and EN measurements, together with the relative contribution of the non-stationarities from the ORPEIS measurements over the course of 24 hours, are presented.

Initially the system is behaving in a non-stationary fashion, as observed from the high relative contribution of the non-stationarities in the mid frequency (III and IV) ranges. This is reflected in the unstable $R_{p}$ values obtained from EIS experiments and the high absolute errors on the $R_{p}$ values obtained from both EIS and LPR experiments initially. After 2 hours of immersion, the fluctuations in the $R_{p}$ values from EIS disappear, reaching a value of $2.85 \pm 0.42 \mathrm{k} \Omega \mathrm{cm}^{2}$. At the same time, the $R_{p}$ value from LPR reaches a value of $1.50 \pm 0.47$ $\mathrm{k} \Omega \mathrm{cm}^{2}$. In the following hours the $\mathrm{R}_{\mathrm{p}}$ value follow a similar trend and decrease toward a stable value of $1.32 \pm 0.12 \mathrm{k} \Omega \mathrm{cm}^{2}$ in the case of LPR measurements and $1.84 \pm 0.23 \mathrm{k} \Omega \mathrm{cm}^{2}$ in the case of EIS measurements after 6.5 hours of immersion. At the same time, the relative contribution of the non-stationarities in the mid frequency regions reaches a minimum, almost four order of magnitude lower compared to the magnitude of the impedance modulus. At this moment, the electrochemical system with corrosion inhibitor is behaving fully stationary. At a later stage, the electrochemical system is considered stable, reflected in stable values of $R_{p}$ from both LPR and EIS measurements. 


\section{Conclusions}

Comparison of the characteristic information obtained from the electrochemical techniques applied in this work makes it possible to position the electrochemical techniques in the time-domain. A distinction between three different characteristic factors of time can be made. Firstly the measurement time, i.e. the time to perform the electrochemical measurement. Secondly the possibility to provide timeresolved information, i.e. electrochemical information in the time domain. Thirdly the possibility to provide frequency-resolved information and consequently differentiation between different electrochemical processes with different characteristic time-constants.

PP measurements provide mechanistic information of the anodic and cathodic stationary behavior of an inhibited electrochemical system after specific periods of immersion, basically a snapshot in time. These measurements, taking approximately 10 minutes for the evaluation of a potential range of $[-30,+500]$ or $[+30,-500] \mathrm{mV}$ versus the $\mathrm{OCP}$ at a scan rate of $1 \mathrm{mV} / \mathrm{s}$, are time intensive if also time-resolved information on inhibitor performance is of interest.

The approach of applying LPR experiments every hour superimposed on a continuous OCP measurement provides a non-invasive and faster alternative to the PP technique, due to the small amplitude of the excitation signal ( $\pm 5 \mathrm{mV}$ versus the $\mathrm{OCP}$ ). This provides the possibility to characterize the electrochemical system in terms of the $R_{p}$ over time. However, no frequency-resolved information can be obtained. Compared to the PP measurements, any mechanistic information is lost.

EIS measurements can both characterize the overall performance of the electrochemical system over time as well as provide details about the corrosion inhibition mechanism and the related time-constants. However, the presence of non-linearities and non-stationarities may cause problems in the interpretation of EIS data since fulfilment of the linearity and stationarity is assumed de facto by applying only an excitation signal with a small amplitude in the stationary regime of the electrochemical process.

Characterization of the electrochemical system through EN measurements provides non-stationarity information about the electrochemical system over time. Conversion of this information into the calculation of the $R_{n}$ provides semi-quantitative information about the inhibition of the electrochemical system averaged over a certain time frame but is unsuccessful in quantitatively describing the electrochemical system at specific discrete times of exposure.

ORP-EIS measurements were applied to provide information about the time-invariance (stationarity) of inhibitor containing electrochemical processes over time. The differences in polarization resistance obtained from the other techniques after 1.5 hours of immersion can be attributed to the presence of non-stationarities and a consequently 'unstable' electrochemical system. In terms of stability it needs to be remarked that the addition of corrosion inhibitors in the electrolyte stabilizes the electrochemical interface as compared to the system without corrosion inhibitors.

Comparison of all results revealed that there is a relation between the $R_{p}$ values from LPR and EIS on the one hand and the relative contribution of the non-stationarities from ORP-EIS on the other hand. The presence of non-stationarities in the initial stages after immersion and the related unstable behavior of the electrochemical processes is linked to the fluctuations and the scatter in the $R_{p}$ values from LPR and EIS measurements. When the non-stationarities disappear, and the system can be considered as a stable electrochemical system, also the $R_{p}$ values become stable as a function of time. However, no agreement was found with the polarization resistance values obtained from EN measurements.

\section{Acknowledgments}

This research was carried out under project number F81.6.13503 in the framework of the Partnership Program of the Materials innovation institute M2i (www.m2i.nl) and the Foundation for Fundamental Research on Matter (FOM), which is part of the Netherlands Organi- zation for Scientific Research NWO (www.nwo.nl). Ruud Hendrikx at the Department of Materials Science and Engineering of the Delft University of Technology is acknowledged for the X-ray analysis.

\section{ORCID}

M. Meeusen (1D https://orcid.org/0000-0002-9658-3049

M. Lekka (1D https://orcid.org/0000-0001-6811-3843

J. M. C. Mol @ https://orcid.org/0000-0003-1810-5145

\section{References}

1. I. M. Baghni, S. B. Lyon, and B. Ding, "The effect of strontium and chromate ion on the inhibition of zinc." Surface and Coatings Technology, 185(2-3), 194 (2004).

2. J. Sinko, "Challenges of chromate inhibitor pigments replacement in organic coatings." Progress in Organic Coatings, 42, 267 (2001).

3. O. Gharbi, S. Thomas, C. Smith, and N. Birbilis, "Chromate replacement: what does the future hold ?." Materials Degradation, 12, 23 (2018).

4. C. Brett and A. M. Brett, Electrochemistry Principles, Methods and Applications., Oxford university press (Vol. 1) (1993).

5. R. W. Revie, (2008). Corrosion and Corrosion control an introduction to corrosion science and engineering.

6. R. L. Twite and G. P. Bierwagen, "Review of alternatives to chromate for corrosion protection of aluminium aerospace alloys," Progress in organic coatings, 33, 91 (1998).

7. G. S. Frankel, "Electrochemical Techniques in Corrosion: Status, Limitations," Journal of testing and evaluation, 42, 1 (2015).

8. V. I. Pokhmurs'kyi, I. M. Zin', S. B. Layon, and L. M. Bilyi, "Synergistic effect of phosphate and calcium-containing pigments on the corrosion resistance of galvanized steel." Materials Science, 39(2), 153 (2003).

9. I. M. Zin, S. B. Lyon, and V. I. Pokhmurskii, "Corrosion control of galvanized steel using a phosphate/calcium ion inhibitor mixture." Corrosion Science, 45(4), 777 (2003).

10. F. Deflorian, I. Felhosi, S. Rossi, L. Fedrizzi, and P. L. Bonora, "Performance of primers containing polyphosphate-based ion-exchange pigments for the protection of galvanised steel." Macromolecular Symposia, 187, 87 (2002).

11. I. A. Kartsonakis, S. G. Stanciu, A. A. Matei, R. Hristu, A. Karantonis, and C. A. Charitidis, "A comparative study of corrosion inhibitors on hot-dip galvanized steel." Corrosion Science, 112, 289 (2016).

12. L. A. Hernandez-Alvarado, L. S. Hernandez, J. M. Miranda, and O. Dominguez, "The protection of galvanised steel using a chromate-free organic inhibitor." Anti-Corrosion Methods and Materials, 56(2), 114 (2009).

13. G. E. Badea, A. Caraban, M. Sebesan, P. Cret, and A. Setel, "Polarisation Measurements Used for Corrosion Rates Determination." Journal of Sustenable Energy, 1(1), 1 (2010).

14. ASTM G59-97. Standard Test Method for Conducting Potentiodynamic Polarization Resistance Measurements. ASTM, 1 (2014).

15. F. Mansfeld, "Fundamental aspects of the polarization resistance technique-the early days." Journal of Solid State Electrochemistry, 13(4), 515 (2009).

16. L. A. Hernandez-Alvarado, L. S. Hernandez, and S. L. Rodriguez-Reyna, "Evaluation of corrosion behavior of galvanized steel treated with conventional conversion coatings and a chromate-free organic inhibitor." International Journal of Corrosion, 1 (2012).

17. E. P. M. van Westing, G. M. Ferrari, and J. H. W. de Wit, "The determination of coating performance with impedance measurements-IV. Protective mechanisms of anticorrosion pigments." Corrosion Science, 36(8), 1323 (1994).

18. I. M. Zin, R. L. Howard, S. J. Badger, J. D. Scantlebury, and S. B. Lyon, "The mode of action of chromate inhibitor in epoxy primer on galvanized steel," Progress in Organic Coatings, 33, 203 (1998)

19. M. Arundell, B. Anil, M. S. Yeoman, K. H. Parker, and D. O. Õ. Hare, "Hilbert transform of voltammetric data," Electrochemistry communications, 6, 366 (2004).

20. Y. Van Ingelgem, E. Tourwé, O. Blajiev, R. Pintelon, and A. Hubin, "Advantages of odd random phase multisine electrochemical impedance measurements." Electroanalysis, 21(6), 730 (2009).

21. D. D. Macdonald, "Application of Kramers-Kronig Transforms in the Analysis of Electrochemical Systems." Journal of The Electrochemical Society, 132(10), 2316 (1985).

22. B. A. Boukamp and J. Ross Macdonald, "Alternatives to Kronig-Kramers transformation and testing, and estimation of distributions." Solid State Ionics, 74(1-2), 85 (1994).

23. B. A. Boukamp, "Practical Application of the Kramers-Kronig Transformation on Impedance Measurements in Solid-State Electrochemistry." Solid State Ionics, 62(12), 131 (1993)

24. Y. Hamlaoui, F. Pedraza, and L. Tifouti, "Corrosion monitoring of galvanised coatings through electrochemical impedance spectroscopy," Corrosion Science, 50, 1558 (2008).

25. M. Meeusen, P. Visser, L. Fernández Macía, A. Hubin, H. Terryn, and J. M. C. Mol, "The use of odd random phase electrochemical impedance spectroscopy to study lithium-based corrosion inhibition by active protective coatings." Electrochimica Acta, 278, 363 (2018).

26. R. A. Cottis, A. M. Homborg, and J. M. C. Mol, "The relationship between spectral and wavelet techniques for noise analysis." Electrochimica Acta, 202, 277 (2016). 
27. A. M. Homborg, T. Tinga, X. Zhang, E. P. M. Van Westing, P. J. Oonincx, G. M. Ferrari, and J. M. C. Mol, "Transient analysis through Hilbert spectra of electrochemical noise signals for the identification of localized corrosion of stainless steel." Electrochimica Acta, 104, 84 (2013).

28. A. M. Homborg, E. P. M. Van Westing, T. Tinga, G. M. Ferrari, X. Zhang, J. H. W. De Wit, and J. M. C. Mol, "Application of transient analysis using Hilbert spectra of electrochemical noise to the identification of corrosion inhibition." Electrochimica Acta, 116, 355 (2014).

29. A. M. Homborg, C. F. Leon Morales, T. Tinga, J. H. W. De Wit, and J. M. C. Mol, "Detection of microbiologically influenced corrosion by electrochemical noise transients." Electrochimica Acta, 136, 223 (2014).

30. T. Breugelmans, E. Tourwé, J. B. Jorcin, A. Alvarez-Pampliega, B. Geboes, H. Terryn, and A. Hubin, "Odd random phase multisine EIS for organic coating analysis." Progress in Organic Coatings, 69(2), 215 (2010).

31. L. Fernández Macía, M. Petrova, T. Hauffman, T. Muselle, T. Doneux, and A. Hubin, "A study of the electron transfer inhibition on a charged self-assembled monolaye modified gold electrode by odd random phase multisine electrochemical impedance spectroscopy." Electrochimica Acta, 140, 266 (2014).

32. L. Fernández Macía, M. Petrova, and A. Hubin, "ORP-EIS to study the time evolution of the $\left[\mathrm{Fe}(\mathrm{CN})_{6}\right]^{3-} /\left[\mathrm{Fe}(\mathrm{CN})_{6}\right]^{4-}$ reaction due to adsorption at the electrochemical interface." Journal of Electroanalytical Chemistry, 737, 46 (2015).

33. A. Alvarez-Pampliega, T. Hauffman, M. Petrova, T. Breugelmans, T. Muselle, K. Van Den Bergh, J. De Strycker, H. Terryn, and A. Hubin, "Corrosion study on Alrich metal-coated steel by odd random phase multisine electrochemical impedance spectroscopy." Electrochimica Acta, 124, 165 (2014).

34. T. Hauffman, T. Breugelmans, Y. Van Ingelgem, E. Tourwé, H. Terryn, and A. Hubin, "Measuring the adsorption of ethanol on aluminium oxides using odd random phase multisine electrochemical impedance spectroscopy." Electrochemistry Communications, 22(1), 124 (2012).

35. T. Hauffman, Y. Van Ingelgem, T. Breugelmans, E. Tourwé, H. Terryn, and A. Hubin, "Dynamic, in situ study of self-assembling organic phosphonic acid monolayers from ethanolic solutions on aluminium oxides by means of odd random phase multisine electrochemical impedance spectroscopy." Electrochimica Acta, 106, 342 (2013).

36. T. Breugelmans, E. Tourwé, Y. Van Ingelgem, J. Wielant, T. Hauffman, R. Hausbrand, R. Pintelon, and A. Hubin, "Odd random phase multisine EIS as a detection method for the onset of corrosion of coated steel." Electrochemistry Communications, 12(1), 2 (2010).

37. G. Ji, L. F. Macía, B. Allaert, A. Hubin, and H. Terryn, "Odd Random Phase Electrochemical Impedance Spectroscopy to Study the Corrosion Behavior of Hot Dip $\mathrm{Zn}$ and Zn-Alloy Coated Steel Wires in Sodium Chloride Solution." Journal of The Electrochemical Society, 165(5), C246 (2018).

38. K. Przywecka, B. Grzmil, K. Kowalczyk, and J. Sreńscek-Nazzal, "Studies on preparation of phosphate pigments for application in composite protective coatings.' Progress in Organic Coatings, 119, 44 (2018).

39. T. J. Cole, "Too many digits: the presentation of numerical data," Arch Dis Child, 100, 608 (1984).
40. R. Kordi, "Sports Medicine Update," Scandinavian Journal of Medicine and Science in Sports, 21, 867 (2011).

41. ASTM. ASTM G3-89 Standard Practice for Conventions Applicable to Electrochemical Measurements in Corrosion Testing, ASTM, 89, 1 (1999).

42. A. M. Homborg, T. Tinga, X. Zhang, E. P. M. Van Westing, P. J. Oonincx, J. H. W. De Wit, and J. M. C. Mol, "Time-frequency methods for trend removal in electrochemical noise data." Electrochimica Acta, 70, 199 (2012).

43. A. M. Homborg, R. A. Cottis, and J. M. C. Mol, "An integrated approach in the time, frequency and time-frequency domain for the identification of corrosion using electrochemical noise." Electrochimica Acta, 222, 627 (2016).

44. E. Van Gheem, R. Pintelon, J. Vereecken, J. Schoukens, A. Hubin, P. Verboven, and O. Blajiev, "Electrochemical impedance spectroscopy in the presence of non-linear distortions and non-stationary behavior Part I: Theory and validation." Electrochimica Acta, 49(26), 4753 (2004).

45. R. A. Buchanan and E. E. Stansbury, Handbook of Environmental Degradation of Materials, (2012).

46. K. M. Ismail, "Evaluation of cysteine as environmentally friendly corrosion inhibitor for copper in neutral and acidic chloride solutions." Electrochimica Acta, 52(28), 7811 (2007).

47. M. Mouanga and P. Berçot, "Comparison of corrosion behavior of zinc in $\mathrm{NaCl}$ and in $\mathrm{NaOH}$ solutions; Part II: Electrochemical analyses." Corrosion Science, 52(12), 3993 (2010).

48. V. Barranco, S. Feliu, and S. Feliu, "EIS study of the corrosion behavior of zinc-based coatings on steel in quiescent $3 \% \mathrm{NaCl}$ solution. Part 1: Directly exposed coatings." Corrosion Science, 46(9), 2203 (2004).

49. C. Deslouis, "The kinetics of zinc dissolution in aerated sodium sulfate solutions. A measurement of the corrosion rate by impedance techniques." Corrosion Science, 29(1), 13 (1989).

50. Da Silva, P. S. G., A. N. C. Costa, O. R. Mattos, A. N. Correia, and P. De Lima-Neto, "Evaluation of the corrosion behavior of galvannealed steel in chloride aqueous solution and in tropical marine environment." Journal of Applied Electrochemistry, 36(3), 375 (2006).

51. M. L. Zheludkevich, K. A. Yasakau, A. C. Bastos, O. V. Karavai, and M. G. S. Ferreira, "On the application of electrochemical impedance spectroscopy to study the self-healing properties of protective coatings." Electrochemistry Communications, 9(10), 2622 (2007).

52. J. R. Macdonald and E. Barsoukov, Impedance Spectroscopy Theory, Experiment, and Applications. Wiley intersience, (Vol. 125). Wiley-Interscience (2005).

53. Z. Dong, X. Guo, J. Zheng, and L. Xu, "Calculation of noise resistance by use of the discrete wavelets transform." Electrochemistry Communications, 3(10), 561 (2001).

54. R. A. Cottis, "Interpretation of Electrochemical Noise Data," Corrosion, 57(3), 265 (2001).

55. J. F. Chen and W. F. Bogaerts, "The Physical meaning of noise resistance." Corrosion Science, 37(11), 1839 (1995).

56. K. E. Atkinson and J. Wiley, An introduction to numerical analysis, Second Edition (1978). 